Chapman University

Chapman University Digital Commons

ESI Working Papers

Economic Science Institute

2020

\title{
Reference Dependent Prices in Bargaining: An Experimental Examination of Precise First Offers
}

\author{
Erik O. Kimbrough \\ Chapman University, ekimbrou@chapman.edu \\ David Porter \\ Chapman University, dporter@chapman.edu \\ Mark Schneider \\ University of Alabama
}

Follow this and additional works at: https://digitalcommons.chapman.edu/esi_working_papers

Part of the Econometrics Commons, Economic Theory Commons, and the Other Economics Commons

\section{Recommended Citation}

Kimbrough, E.O., Porter, D., Schneider, M. (2020). Reference dependent prices in bargaining: An experimental examination of precise first offers. ESI Working Paper 20-42.

https://digitalcommons.chapman.edu/esi_working_papers/337/

This Article is brought to you for free and open access by the Economic Science Institute at Chapman University Digital Commons. It has been accepted for inclusion in ESI Working Papers by an authorized administrator of Chapman University Digital Commons. For more information, please contact laughtin@chapman.edu. 


\section{Reference Dependent Prices in Bargaining: An Experimental Examination of Precise First Offers}

\section{Comments}

ESI Working Paper 20-42

This paper later underwent peer review and was published as:

Kimbrough, E.O., Porter, D., Schneider, M. (2021). Reference dependent prices in bargaining: An experimental examination of precise first offers. Journal of Economic Psychology, 86, 102406. https://doi.org/10.1016/j.joep.2021.102406 


\title{
Reference Dependent Prices in Bargaining: An Experimental Examination of Precise First Offers ${ }^{*}$
}

\author{
Erik O. Kimbrough \\ Smith Institute for Political Economy \& Philosophy \\ Chapman University \\ David Porter \\ Economic Science Institute \\ Chapman University \\ Mark Schneider \\ University of Alabama
}

\begin{abstract}
:
Evidence from psychology and marketing suggests that those who make a "precise" first offer in bargaining get a better deal than those who make a "round" first offer. We report on a series of experiments designed to test for and improve our understanding of the "precise first offer" (PFO) effect in bargaining and whether it likely reflects rational optimizing or equilibrium behavior. Our experimental treatments vary whether decisions are incentivized and whether the PFO effect can emerge as an equilibrium of a cheap-talk signaling game. We find evidence of a PFO effect when subjects read a vignette and make unincentivized individual decisions. When monetary incentives are added to the vignette, we still find the PFO effect, but it is not robust. In a bilateral bargaining situation with a cheap-talk equilibrium, we can not find the PFO effect, which is inconsistent with the equilibrium predictions. Moreover, the PFO effect reemerges in a setting in which initial offers are generated by a random device and thus provides a strong refutation of the signaling model. Our evidence suggests that optimizing and equilibrium accounts of the PFO effect are inadequate. Understanding initial offers as reference points, which subtly change perceptions about the kinds of acceptable counteroffers, provides a plausible account of a new finding on which prior explanations are silent: precise offers induce more precise counteroffers.
\end{abstract}

JEL Codes: C7, C9, D9

Keywords: bargaining, precise first offers, reference points

\footnotetext{
* We greatfully acknowledge the support of the Hoag Real Estate Center at Chapman University for funding our experiments. We would like to thank Philipp Limberg and Megan Luetje for help conducting the experiments, and we'd like to apologize to Megan for having to count out all the pennies necessary to keep these precise offers incentive compatible. We received helpful comments from Taylor Jaworski and audiences in the Economic Science Institute Brown Bag Workshop. All remaining errors are our own.
} 


\section{Introduction}

Understanding how people negotiate and the final terms of trade that arise are central challenges in the study of bargaining. Classical economic theory links bargaining power and bargaining outcomes to buyer and seller characteristics (e.g., willingness to pay or accept, time preferences, and risk preferences) and the trading mechanism. For instance, in an offer-counteroffer sequential mechanism, the negotiated price and the delay before reaching an agreement depend on the bargainers' values, discount rates, and outside options.

However, literature from psychology emphasizes that bargaining outcomes may also depend on behavioral factors such as anchors and reference points, which can shape bargainers' expectations and behavior in ways that incentives alone seem unable to explain (e.g., Kahneman 1992). Here, we report a series of studies designed to improve our understanding of one behavioral factor that has been shown to influence bargaining outcomes, the first offer (see, e.g., Kristensen and Garling 2000). ${ }^{1}$

If the first offer can shape the bargaining process, then savvy bargainers should choose these offers wisely to ensure the best possible deal. Should the seller offer a high price to provide significant room for counteroffers? Similarly, for the buyer, should the initial offer be relatively low? While the psychology literature does not offer advice on what the specific initial offer price will or should be, it does provide results about the type of offer that should be submitted. To obtain better counteroffers, the initial offer should be precise (e.g., in lower stakes bargains, it should include cents, and in higher stakes bargains, it ought not to be divisible by 5).

Janiszewski and Uy (2008) conducted an experiment presenting subjects with various scenarios about buying a durable item (e.g., a TV). They find that participants are willing to pay more when sellers post a precise list price, e.g., \$799, instead of a round price, e.g., \$800. The scenarios are not framed as a negotiation but as a prediction of the seller's base cost of the item being offered for sale. Similarly, Thomas et al. (2010) argue that consumers perceive precise prices to be lower than round prices: "In a laboratory pre-test, we find that people incorrectly judge precise prices (e.g., $\$ 325,425$ ) to be lower than round prices of similar magnitudes (e.g.,

\footnotetext{
${ }^{1}$ Oesch and Galinsky 2003 provide a survey of precise first offers as anchors and reference points.
} 
$\$ 325,000)$." They also find in a sample of 27,000 real estate transactions that buyers pay higher sale prices when list prices are precise.

Mason et al. (2013) examined scenarios that are framed as a negotiation and explore "Precise First Offers" (PFOs) and their effect on counteroffers. In their Study 1, subjects are asked to play the role of a seller of a textbook. A hypothetical buyer has made an offer (precise or round), and the subject is asked to provide a counteroffer. They find that PFOs have an anchoring effect on a negotiator's counteroffer. Those who received precise first offers respond with less aggressive counteroffers than those who received round initial offers.

Loschelder et al. (2017) report an experiment in which subject pairs play seller and buyer roles in a negotiation involving the sale of a chemical plant. One subject in each pair was instructed to make the first offer (sometimes the buyer, sometimes the seller). They find that those who made the most precise first offers were given more favorable counteroffers.

Recent explanations of the PFO effect predict that precise offers provide information that is not contained in a round offer. One version of this argument suggests that precise offers are "potent" anchors because they reveal the seller's information about the item's true value (Mason et al. 2013). Similarly, Backus et al. (2019) develop a cheap-talk signaling model in which precise offers provide information about a seller's type (e.g. hard bargainer, high-cost seller, etc.). There is a separating equilibrium in their model in which sellers induce higher negotiated prices with a lower probability of sale by making a precise offer or induce lower negotiated prices with a higher probability of sale by making a round offer. Using eBay's online bargaining interactions, they find that items priced in multiples of $\$ 100$ receive $8 \%$ to $12 \%$ lower offers but are $15 \%$ to $25 \%$ more likely to sell.

In this paper, we investigate whether the PFO effect likely reflects rational optimizing or equilibrium behavior. We begin by replicating the PFO effect (based on treatment $1 \mathrm{~d}$ of Mason et al., 2013). We then extend this replication by adding a monetary incentive to the decision. If choices in the presence of monetary incentives are more likely to induce optimizing behavior, 
then the presence or absence of the PFO effect with monetary incentives provides an indication of whether the PFO effect is driven by optimizing behavior.

Next, we create a bargaining experiment to test both the cheap-talk signaling model of the PFO effect from Backus et al. (2019) and the anchoring explanation due to Mason et al. In the experiment, seller subjects (with an outside option drawn from a distribution) make an initial offer, and buyer subjects can accept or make a counteroffer. Unknown to buyers, we restrict the set of offers available to the sellers to control whether the sellers make a round or precise first offer in each bargain. Specifically, they choose between two possible offers, one higher and one lower (but both round or both precise in each negotiation). We employ a perfect stranger matching protocol such that each buyer interacts with each seller exactly once over twelve periods of pairings. This is the "Chosen" treatment, and it allows us to assess whether the PFO effect persists in bilateral bargaining settings in which human subjects (rather than computers) are on both sides of the market. Importantly, it is also designed to construct a situation in which precise offers can plausibly be seen (by buyers) as a signal of a seller's willingness to budge from the initial price. This will test the robustness of PFOs in a market context and whether the PFO effect is consistent with equilibrium signaling behavior.

To directly test explanations in which PFOs arise because a precise offer contains information, we conduct a second treatment using the exact same protocols, except that the seller's initial offer is commonly known to be selected randomly rather than by the seller. Since the offer is determined randomly, it cannot signal any information, and so the PFO effect cannot result from such an equilibrium in this treatment. As before, we experimentally control the set of offers that might be randomly chosen, and in each negotiation, the two possible offers are either both precise or both round, so we control whether the offers are round or precise.

Using the Mason et al. vignette, we replicate the PFO effect without incentives, but find that the effect is not robust under monetary incentives. In addition, we find no PFO effect in the market experiment when sellers endogenously choose their initial offers, but we find evidence of the PFO effect when the initial offer is randomly selected, both of which are inconsistent with the 
signaling model. Our findings suggest that the PFO effect does not reflect rational optimizing or equilibrium behavior.

\section{Experimental Design}

\section{A. Replication of Study 1d from Mason et al. (2013)}

We perform a replication of Study 1d reported by Mason et al. (2013). Before testing possible explanations for the effect, we first wanted to confirm that it replicates. The experiment asks subjects to play a role in a hypothetical vignette depicting two people bargaining over a used textbook price. In the vignette, the subject plays the role of a seller who has posted an ad for an introductory statistics textbook, asking for the buyer's best offer. A buyer has made an offer $o$, and the seller is asked to provide a counteroffer $c$. The experimental treatment varies whether the buyer's offer is round $(o=\$ 20.00)$ or precise $(o=\$ 19.85$ or $\$ 20.15)$. The vignette's complete text is displayed below (complete instructions can be found in Appendix B).

You are a college student at the University of Florida. The semester has just ended, and your Introductory Statistics class is over. Because you spent $\$ 50$ of your hard-earned money buying the statistics textbook at the beginning of the semester, you are hoping to recoup some of the cost by reselling it to another student.

Earlier in the week, you posted the textbook on an online site that allows University of Florida students to resell their used textbooks. The ad read "Introductory Statistics textbook for sale. Best offer." You have just received a message from a potential buyer interested in purchasing the book.

In the message he says that he will give you $\$\{19.85,20.00,20.15\}$ for the textbook.

The lowest amount of money for which you are willing to part with the textbook is \$19. You have the opportunity to make a counteroffer.

The buyer is willing to pay more than he offered, but you are not sure how much more he is willing to pay. If your counteroffer is below the most the buyer is willing to pay for your textbook, the sale takes place at that price, and you receive the amount you offered minus $\$ 19$ (which is the lowest amount of money for which you are willing to part with the textbook). 
If your counteroffer is above the most the buyer is willing to pay for your textbook, no sale takes place, and you and the buyer each receive $\$ 0$.

Please enter your counteroffer:

The PFO effect is identified by computing the difference $(d)$ between the first offer $(o)$ and the counteroffer (c): $d=o-c$ and comparing the magnitude of $d$ across offer treatments. The PFO effect predicts that $d$ will be larger when $o$ is a round offer (i.e. \$20.00) than when $o$ is a precise offer (i.e. $\$ 19.85$ or $\$ 20.15$ ). That is, subjects will bargain harder with a (hypothetical) counterpart who makes a round offer.

Hypothesis 1: The PFO effect replicates (d is larger with a round offer relative to a precise offer)

We recruited 160 subjects to our laboratory to participate in the replication of Mason et al. (2013). Subjects were seated at visually isolated computer terminals where they privately read computerized instructions. Eighty subjects were assigned to participate in this replication without incentives. In addition to our standard show-up payment for arriving at the experiment on time, subjects were told that they would receive $\$ 5$ for completing the experiment. The instructions text also stated "Your choices will not affect the final payment you receive." The other eighty subjects were assigned to participate in a version of the replication where subjects were paid based on monetary incentives, as described below. Within each type of replication (with or without monetary incentives), subjects were equally likely to be assigned one of the three textbook values $\{\$ 19.85, \$ 20.00$, or $\$ 20.15\}$ by the computer. Without incentives, 27 subjects were assigned a value of $\$ 19.85,27$ subjects were assigned a value of $\$ 20.15$, and 26 were assigned a value of $\$ 20$. With incentives, 27 subjects were assigned a value of $\$ 19.85,26$ were assigned a value of $\$ 20.15$, and 27 were assigned a value of $\$ 20$.

\section{B. Incentivized Treatment of Study 1d from Mason et al. (2013)}

As noted above, eighty subjects participated in a version of the replication that tests the PFO effect's robustness by introducing incentives. Since our replication of Mason et al. (2013) 
described above was unincentivized, one concern is that the observed effect is an artifact of the vignette that would dissipate with monetary incentives based on outcomes. Thus, we used the same vignette, but we minimally altered the introductory text of the instructions to indicate to subjects that their choices did determine their payoffs: "Your choices will affect the final payment you receive." In particular, if the fictitious buyer accepted the counteroffer, the subject received the counteroffer minus $\$ 19$ (subject's opportunity cost). The procedures were otherwise identical to those of the replication (instructions can be found in Appendix B). 80 subjects participated in this treatment; as in the replication, we identify the PFO effect by comparing the value of $d$ across the precise and round first offers. Here, subjects' payments varied depending on their counteroffer and whether it was accepted. To assure incentive compatibility at the margin, we paid subjects in increments down to pennies.

Hypothesis 2: Incentivizing the Vignette Study does not eliminate the PFO effect (d is larger with a round offer relative to a precise offer)

\section{Treatments of PFO in a Market Context with a Cheap-talk Equilibrium}

\section{i. Robustness of PFO in a Market Context}

In this treatment, we examine the effect of PFO in a natural market/bargaining setting in which human buyers and sellers interact. This is the setting required to examine the cheap-talk model of Backus et al. (2019). In their model, the PFO effect can arise because it can signal the seller's willingness to bargain. Those less willing to bargain make precise offers, while those more inclined to bargain submit round offers.

In each period, subjects interacted in pairs: one buyer and one seller. To induce heterogeneity in willingness to bargain, sellers had outside options that allowed them to sell the item to the experimenter for either $\$ 0$ or $\$ 9$, with equal probability, should they not reach an agreement with the buyer. Subjects assigned the role of buyers were informed that sellers had either a high or low outside option at which they could sell the item if they did not sell it to the buyer. However, the precise value of the outside option was a seller's private information. This setup provides the heterogeneity for sellers to signal high or low outside options with their initial offers. Buyers 
had induced values of $v=\$ 21, \$ 22, \$ 23, \$ 24, \$ 25$, or $\$ 26$ each with equal probability; this was their private information. Sellers made an initial offer $o$ to buyers, and buyers were allowed to make a counteroffer $c$. If buyers wanted to purchase at the initial offer price, they needed to counteroffer at the same price as the initial offer. If buyers wanted to buy for less, they could make a lower counteroffer, which was then passed to the seller as a take-it-or-leave-it final offer. We call this treatment Chosen since sellers must choose an offer.

In this treatment, unknown to the buyers, the sellers' set of possible initial offers was constructed by the experimenter. We created 12 pairs of initial offers, where both offers in a pair were either round or precise. For each pair of round offers, two symmetric pairs of precise offers were higher or lower than the round offers by a fixed amount (e.g. $\{14.78,19.78\},\{15.00,20.00\},\{15.22$, $20.22\}) .^{2}$

In each period of the Chosen treatment, the seller would see one pair of offers and was asked to choose one of the two offers to send to the buyer. Thus, the seller did choose the offer, but the restricted choice set ensured that we had experimental control over whether that offer was round or precise. Figure 1a shows the seller's screen, while Figure 1b shows the buyer's screen.

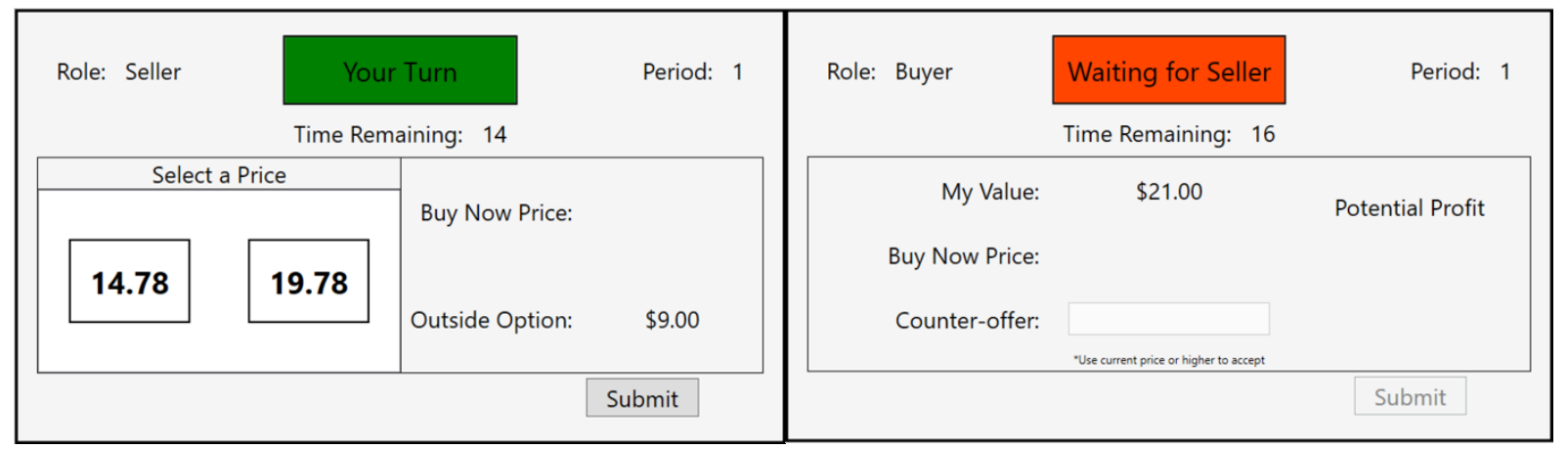

(a) Seller

(b) Buyer

Figure 1. Screenshots from the Initial Offer Phase of the Chosen Treatment

\footnotetext{
${ }^{2}$ In our first 8 sessions, a typo in the parameter file introduced one asymmetric precise offer. That is, one of the triples was $\$ 15.94, \$ 15, \$ 15.06$ when it should have been $\$ 14.94, \$ 15, \$ 15.06$. We corrected the parameter file for the final 8 sessions. We exclude all initial offers of $\$ 15.94$ from our analysis, since they do not have a paired round offer of $\$ 16$ for comparison, though our results are qualitatively unchanged if we do not exclude these offers.
} 
Hypothesis 3: In a market context, when sellers choose their offer, there is a PFO effect (d is larger with a round offer relative to a precise offer)

We conducted 8 sessions with 24 subjects each. Subjects were seated at visually isolated computer terminals where they read computerized instructions privately. Instructions were delivered privately to preserve the information asymmetry between Buyers and Sellers, facilitating our main treatment comparison. At the end of the instructions, subjects completed a quiz meant to ensure comprehension. Subjects were paid $\$ 0.50$ for each correct answer. The quizzes for buyers and sellers are both in Appendix B.

Subjects were assigned to be buyers or sellers prior to the first period and remained in that role throughout the session. We implemented a perfect stranger matching protocol in which each buyer interacted with each seller exactly once. We ensured that each seller chose her initial offer once from each of the 12 pairs of offers. This means we can identify the PFO effect withinsubject. Subjects were paid for one randomly chosen period, again using increments down to one penny to preserve incentive compatibility at the margin. Sessions lasted approximately 1 hour, and subjects earned an average of \$21.81, including the \$7 payment for arriving at the experiment on time, their earnings from the quiz, and their earnings from one randomly chosen period.

\section{ii. A direct test of information-based explanations (Random treatment)}

In this treatment, seller offers were chosen at Random. In particular, it was common knowledge that the offer was chosen at random by a computer. However, just as in the Chosen treatment, the computer selected the random offer from one of the 12 preconstructed pairs of offers in each period. Again, this detail was known to the seller but not to the buyer, and this allows us to directly compare the Random and Chosen treatments. Figure 2a shows the seller's screen, and Figure $2 \mathrm{~b}$ shows the buyer's screen while the initial offer is being randomized in the Random treatment. All other aspects of the experiment were identical to the Chosen treatment. We conducted 8 sessions with 24 subjects each. Sessions lasted approximately 1 hour, and subjects 
earned an average of $\$ 22.02$, including the $\$ 7$ payment for arriving at the experiment on time, their earnings from the quiz, and their earnings from one randomly chosen period.

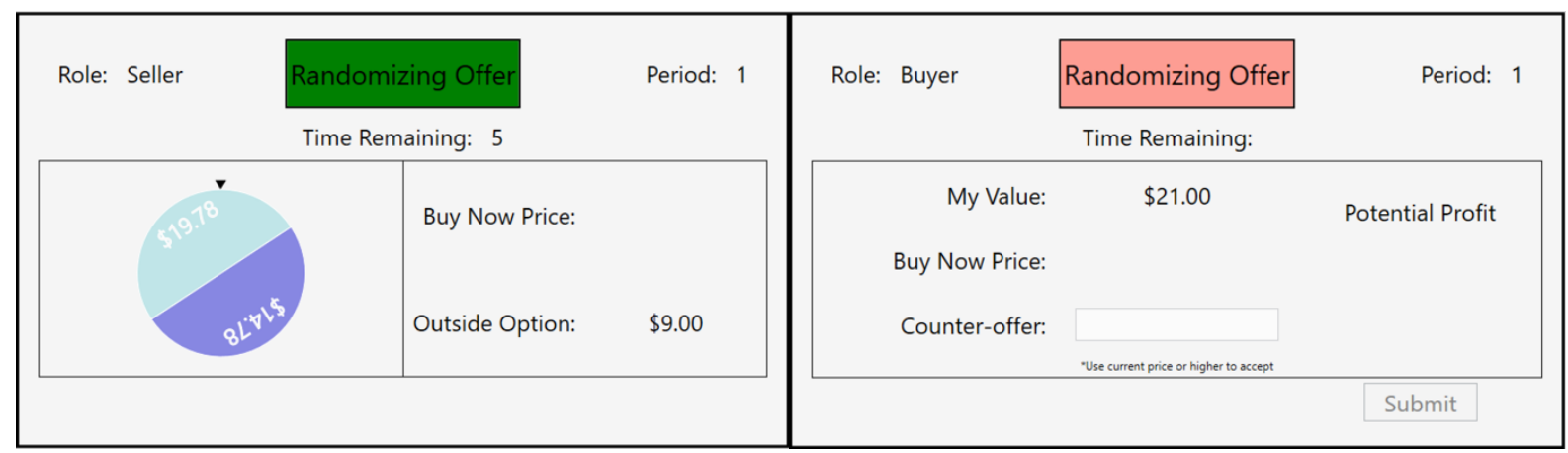

(a) Seller

(b) Buyer

Figure 2. Screenshots from the Initial Offer Phase of the Random Treatment

Both the anchoring and signaling explanations predict no PFO effect in the Random treatment since a randomly determined offer cannot contain information.

Hypothesis 4: In the Random treatment, there will be no PFO effect (d will be the same with both round offers and precise offers)

\section{iii. Subject Characteristics}

At the end of each session of the Random and Chosen treatments, subjects completed a survey that included demographic questions, the Cognitive Reflection Test, and measures of risk preference and optimism, a political identity question, and a question about their program of study. ${ }^{3}$ The full survey is reproduced in Appendix C. We will use these tests to find any distinct correlates with offer-counteroffer behavior.

\footnotetext{
${ }^{3}$ The political question and program of study question were asked only to facilitate recruitment to future unrelated studies. One of the authors of this study is grateful to his coauthors for allowing him to tack these on.
} 


\section{Results}

Our primary measure for the PFO effect is $d=o-c$, where o is the initial offer by the seller and $\mathrm{c}$ is the counteroffer of the buyer.

\section{A. Replication Study and Incentivized Treatment}

Across the 160 subjects in our replication and incentivized treatments, three responded with a counteroffer for which their maximum possible profit was less than or equal to zero. Excluding these subjects, we have 157 subjects across treatments. In the direct replication, subjects were not paid based on monetary incentives to keep our design consistent with Mason et al.'s original study. The results of the replication and incentivized treatments can be found in Table 1 . In the replication, the average counteroffer among subjects who observed the $\$ 19.85$ initial offer was $\$ 25.85$, compared with an average counteroffer of $\$ 24.69$ among subjects who saw the $\$ 20.15$ initial offer. This difference is not significant ( $\mathrm{p}=0.174$, two-tailed Mann-Whitney $\mathrm{U}$ test), indicating that for these small margins, there is no difference in counteroffers due to the magnitude of the precise initial offer. Thus we pool data from both precise offers when computing $d$. The mean of $d_{\text {precise }}=\$ 5.25$.

\section{Replication $\quad$ Incentivized \\ Initial Offer Initial Offer}

\begin{tabular}{lcccccc} 
& Round & \multicolumn{2}{c}{ Precise } & Round & \multicolumn{2}{c}{ Precise } \\
\hline Offer $(\boldsymbol{o})$ & $\$ 20.00$ & $\$ 19.85$ & $\$ 20.15$ & $\$ 20.00$ & $\$ 19.85$ & $\$ 20.15$ \\
Counteroffer $(\boldsymbol{c})$ & $\$ 27.13$ & $\$ 25.85$ & $\$ 24.69$ & $\$ 26.44$ & $\$ 24.52$ & $\$ 25.64$ \\
Difference $(\boldsymbol{d})$ & $\$ 7.13$ & \multicolumn{2}{c}{$\$ 5.25$} & $\$ 6.44$ & $\$ 5.07$ \\
\hline p-value & & 0.05 & & & 0.17
\end{tabular}

Table 1. Mean Counteroffer Statistics by Treatment and Offer Type 
By contrast, the average counteroffer for subjects who observed the round $\$ 20$ initial offer was $\$ 27.13$. Thus the mean of $d_{\text {round }}=\$ 7.13 .{ }^{4}$ To test for the PFO effect, we compare $d$ across precise and round offers. We find that $d_{\text {round }}$ is significantly larger than $d_{\text {precise }}(\mathrm{p}=0.05$, two-tailed Mann-Whitney U test), confirming the existence of the precise offer effect in an unincentivized vignette, consistent with the original study.

Finding 1: The PFO effect is replicable in a non-incentivized vignette study.

In the incentivized treatment, we again find no significant difference in counteroffers to the two precise initial offers ( $p=0.159$, two-tailed Mann-Whitney $U$ test $)$ indicating there is no detectable effect of initial offer magnitude for our precise initial offers. Thus we again pool over both precise offers when calculating $d$. The mean of $d_{\text {precise }}$ is $\$ 5.07$ and the mean of $d_{\text {round }}$ is $\$ 6.44$. While this evidence is qualitatively consistent with a PFO effect, the difference in means is not statistically significant ( $p=0.17$, two-tailed Mann-Whitney $U$ test). Hence, we do not see a significant PFO effect when extending the original study to include monetary incentives.

Finding 2: The PFO effect diminishes (and is not statistically significant) in our incentivized treatment.

While the PFO effect is not significant within the incentivized treatment, there is also no significant difference in counteroffers to either precise or round initial offers across treatments ( $p$ $=0.47$ and $p=0.98$, respectively, two-tailed Mann-Whitney $U$ tests). Thus, we pooled the data from both studies to gain more power to test the PFO effect in vignette studies. Pooling across studies and computing the difference between counteroffers and initial offers for all precise offers (mean $d_{\text {precise }}=\$ 5.16$ ) and all round offers (mean $d_{\text {round }}=\$ 6.78$ ), the PFO effect is statistically significant $(\mathrm{p}=0.01$, two-tailed Mann-Whitney $\mathrm{U}$ test).

\footnotetext{
${ }^{4}$ The differences between the initial and counteroffers we observed are within one standard deviation of those observed by Mason et al. (2013) in their study 1d for both precise and round initial offers (both with and without incentives).
} 
Finding 3: The PFO effect replicates when we pool the data from the hypothetical and incentivized vignette studies.

Findings 1, 2, and 3 indicate that the PFO effect is detectible with and without incentives, although the effect is weaker with incentives. This provides suggestive evidence that nonrational factors and non-optimizing behavior may contribute to the PFO effect.

\section{B. Market Context Treatments}

Recall, in our market context treatments, subjects are randomly paired each market period and each seller (buyer) makes an offer (counteroffer). Each experimental session lasted 12 periods. In this perfect strangers matching protocol, period one is a clean test of a one-shot decision for the cheap-talk model. In addition, we will see if this model is robust when subjects obtain experience across periods.

\section{i. The PFO Effect in Period 1}

For period 1 from the Chosen and Random treatments, we analyzed $d$ when buyers faced precise and round initial offers. ${ }^{5}$ Second, we compute the probability of accepting each type of offer. Table 2 displays period 1 mean $d$ and the mean probability of acceptance by treatment and offer type.

\footnotetext{
${ }^{5}$ In the experiment, a buyer could accept the initial offer only by counteroffering at a price equal to the initial offer. Thus all accepted offers are coded as an initial offer - counteroffer difference of $\$ 0$.
} 


\begin{tabular}{lcccc} 
& \multicolumn{2}{c}{ Offer Difference $(d)$} & \multicolumn{2}{c}{ Prob. Accept } \\
& Chosen & Random & Chosen & Random \\
\hline Round & 2.37 & 3.59 & 0.31 & 0.09 \\
Precise & 1.95 & 1.54 & 0.18 & 0.28 \\
\hline p-value & 0.98 & $<0.01$ & 0.15 & 0.04 \\
\hline
\end{tabular}

Offer difference: Mann-Whitney U test, Pr(Acc.): Proportions Test

Table 2. Period 1 Difference Between Initial and Counteroffer and Probability of Accepting the Initial Offer, by Treatment and Offer Type

We find no evidence of a statistically significant PFO effect in either measure for the Chosen treatment (Mann-Whitney $U$ test, $\mathrm{p}=0.90$ for offer differences, and proportion test, $\mathrm{p}=0.15$ for the probability of acceptance).

Finding 4: Using first-period data in the Chosen treatment, we do not find a PFO effect on either offer differences or probability of acceptance.

Strikingly, we observe a significant PFO effect in period 1 in the Random treatment. This is surprising since the initial offers were commonly known to be generated by a random device. Hence, they cannot serve as an informative signal of the seller's willingness to bargain. We find strong evidence that the gap between initial offers and counteroffers is smaller for precise offers than round offers in the Random treatment ( $\mathrm{p}=0.0001$, two-tailed Mann-Whitney U test). We find evidence that buyers were actually more likely to outright accept a seller's precise initial offer in the Random treatment ( $\mathrm{p}=0.04$, proportions test).

Finding 5: Using first-period data in the Random treatment, we find PFO effects on both offer differences and probability of acceptance.

Combining the above findings, our period 1 analysis also has a broader implication: 
Finding 6: Our evidence is inconsistent with either anchoring or signaling explanations in period 1 since both predict a PFO effect in the Chosen treatment and no PFO effect in the Random treatment, the opposite of what we observe for both treatments.

\section{ii. The PFO Effect Across Periods}

Having conducted an extremely conservative test of the PFO effect using period 1 data, we now exploit our rich panel data set to assess the PFO effect across all 12 periods of bargaining. There are 3 round offers in the experiment around which the precise offers are centered: $\$ 10, \$ 15$, and $\$ 20$. The magnitude of the difference between offer and counteroffer may vary across this range, and the analysis so far ignores this fact. Figure 3 plots the mean difference between the initial offer and counteroffer by offer in the Chosen treatment to address this concern. The figure is broken into three panels, with each panel containing a round offer and its neighborhood's precise offers. Figure 4 shows the same data for the Random treatment. $^{6}$

(a) Initial Offer 10

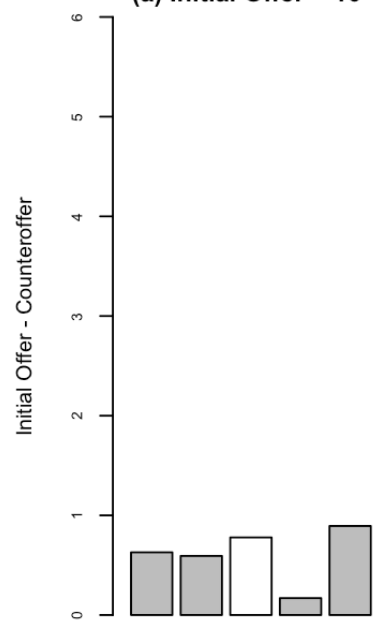

$\begin{array}{lllll}9.83 & 9.91 & 10 & 10.09 & 10.17\end{array}$
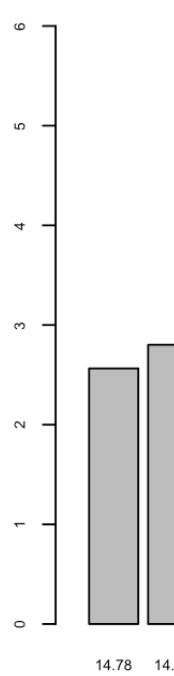

(b) Initial Offer $\sim 15$

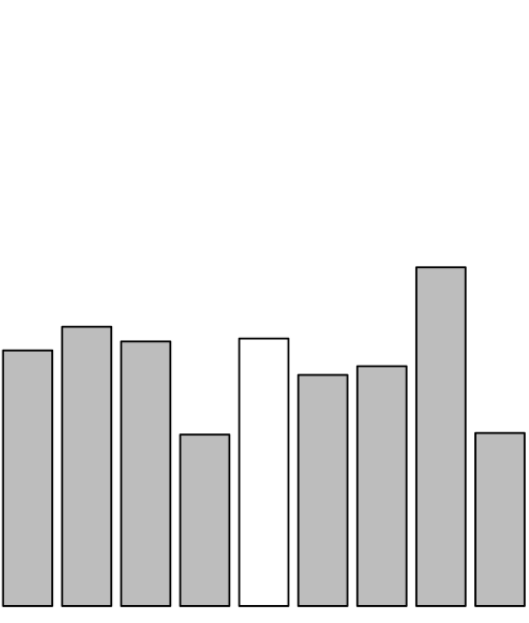

Initial Offer (c) Initial Offer 20

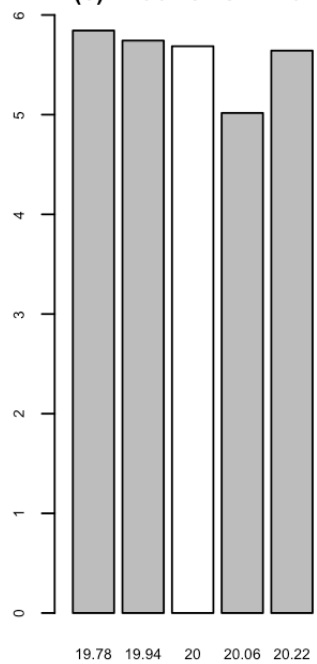

$\begin{array}{lllll}19.78 & 19.94 & 20 & 20.06 \quad 20.22\end{array}$

Figure 3. Mean Difference Between Initial Offer and Counteroffer, Chosen treatment.

\footnotetext{
${ }^{6}$ Appendix A, Figures A1 and A2 show the difference-in-differences: how the offer-counteroffer gap differs for precise offers in the neighborhood of a given round offer, relative to the gap for the round offer (grey - white bars).
} 
(a) Initial Offer $\sim 10$

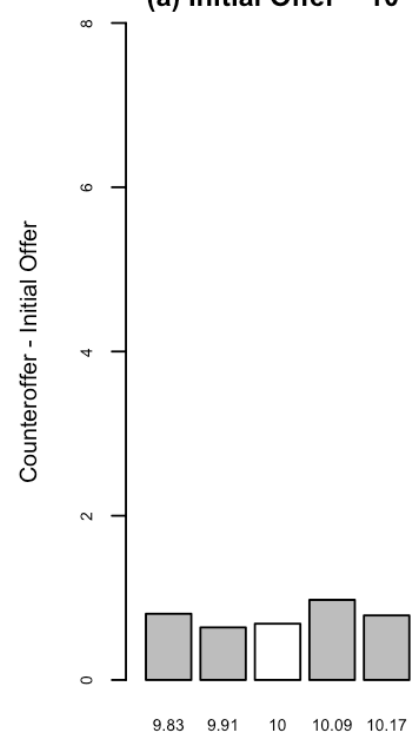

(b) Initial Offer $\sim 15$

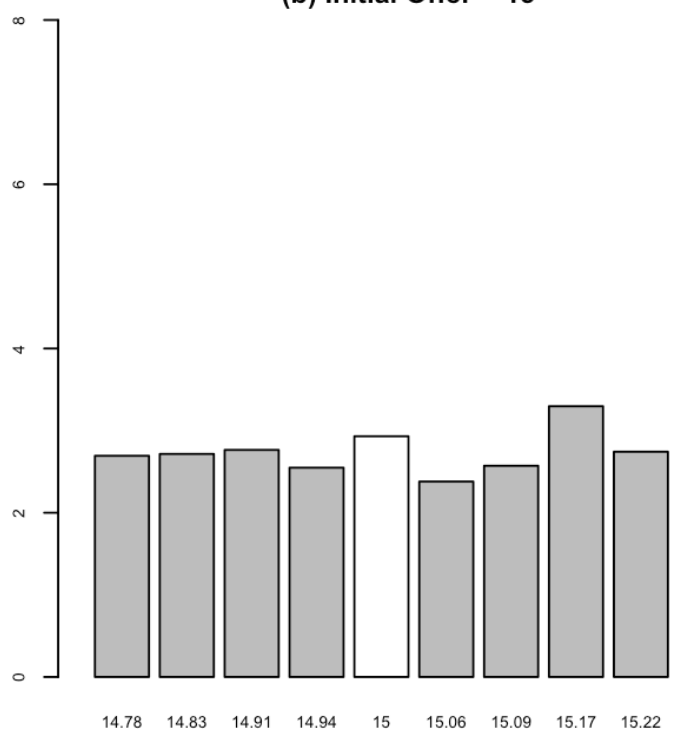

Initial Offer (c) Initial Offer $\sim 20$

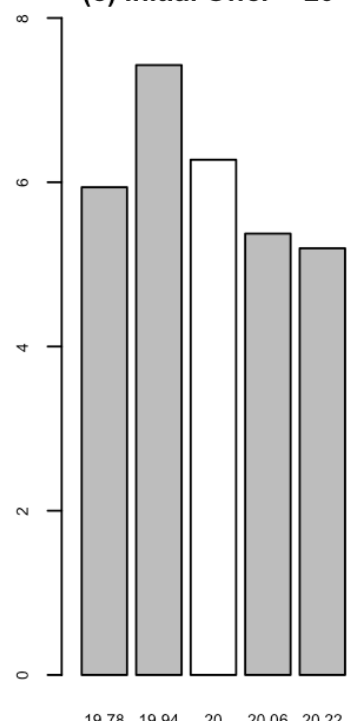

$19.78 \quad 19.94 \quad 20 \quad 20.06 \quad 20.22$

Figure 4. Mean Difference Between Initial Offer and Counteroffer, Random treatment.

Visual inspection does not reveal large PFO effects in either treatment; however, in the Random treatment, the offer - counteroffer difference is systematically smaller for precise offers than round offers in the neighborhood of $\$ 15$ and $\$ 20$. We support the visual evidence by estimating a panel GLS regression model in which the dependent variable is the difference between the initial offer and the counteroffer. The independent variables of interest are a Chosen treatment dummy, a dummy indicating that a buyer received a precise initial offer from the seller, and an interaction term. We also include two additional dummies for the integer value to which the initial offer rounds: i.e. an offer of $\$ 14.94$ rounds to $\$ 15$, so there is a "Rounds to $\$ 15$ " dummy, and an offer of $\$ 20.22$ rounds to $\$ 20$, so there is a "Rounds to $\$ 20 "$ dummy. This means that the constant term captures the offer - counteroffer difference for offers in the neighborhood of $\$ 10$ in the Random treatment. We include random effects for each subject to control for repeated measures, and we cluster standard errors at the subject level.

The results are shown in column (1) of Table 3. While there is a significant and negative PFO effect captured by the Precise Offer dummy, this captures the PFO effect in the Random treatment. The coefficient on the interaction ChosenXPrecise is positive, and we cannot reject the null hypothesis that the PFO effect is equal to zero in the Chosen treatment $(p=0.62$, Wald 
test). Thus, we see evidence of a PFO effect, but only when anchoring and signaling do not predict it.

Table 3. Panel GLS Regressions of the PFO Effect on Offers and Proportion Accepting, by Treatment.

\begin{tabular}{lll} 
& $(1)$ & $(2)$ \\
& $(d)$ & Accepted the Initial \\
& -0.23 & Offer $\{0,1\}$ \\
\hline Chosen & $(0.25)$ & -0.03 \\
Precise Offer & $-0.24 * *$ & $(0.03)$ \\
& $(0.11)$ & $-0.05^{* *}$ \\
Chosen X Precise & 0.17 & $(0.02)$ \\
& $(0.18)$ & 0.03 \\
Offer Rounds to 15 & $1.99 * * *$ & $(0.03)$ \\
& $(0.13)$ & $-0.35^{* * *}$ \\
Offer Rounds to 20 & $5.04 * * *$ & $(0.03)$ \\
& $(0.20)$ & $-0.44 * * *$ \\
Constant & $0.95 * * *$ & $(0.03)$ \\
& $(0.13)$ & $0.55 * * *$ \\
Observations & 2254 & $(0.03)$ \\
R Sq. & 0.318 & 2254 \\
\hline Clustered standard errors in parentheses. $* \mathrm{p}<0.1, * * \mathrm{p}<0.05, * * * \mathrm{p}<0.01$
\end{tabular}

We estimate an analogous model to study the PFO effect on the probability of accepting the initial offer for completeness. In column (2) the dependent variable equals 1 if the buyer accepted the seller's initial offer, and the independent variables are the same as in column (1). While there is a negative and significant PFO effect on the probability of accepting the initial offer in the Random treatment, we cannot reject the null of zero PFO effect in the Chosen treatment $(\mathrm{p}=0.25)$. Thus, as with the subject-level averages above, we see evidence of the PFO effect, but only when anchoring or signaling do not predict it.

Finding 6: Using the data from all periods, we find no PFO effect in the Chosen treatment. In the Random treatment, we find a significant PFO effect. In sum, we find no support for either anchoring or signaling. 
Finally, we conduct regression analyses on the offer-counteroffer difference and the accept decision, including our survey measures of cognitive reflection, risk aversion, and optimism as independent variables, using both period 1 data and the full panel data set. For completeness, we also examine the seller's decision to accept/reject the buyer's counteroffer; these specifications include additional controls for the seller's outside option and the value of $d$. We find no evidence of significant relationships between these psychological measures and bargaining behavior. Regression results are available in Appendix A in Tables A1 and A2.

\section{Discussion and Conclusion}

We conducted experimental tests of the precise first offer effect in bargaining with and without monetary incentives and in a market context with random or endogenously chosen first offers. The experiments collectively provide a test of whether the PFO effect is consistent with rational choice. To the extent that behavior is more rational when real money is on the table, contingent on a person's decisions, the first series of experiments tests whether the PFO effect emerges when incentives for rational decision making are stronger. The second series of experiments tests whether the PFO effect is consistent with a game-theoretic model in which precise offers are informative signals of a seller's willingness to bargain in equilibrium. Although we replicate the PFO effect without monetary incentives, we find that it diminishes and becomes statistically insignificant when introducing monetary incentives. In addition, we find no PFO effect in a market setting designed to test the anchoring explanation of Mason et al. (2013) and the cheap talk signaling model of Backus et al. (2019), but instead, we find a PFO effect in an analogous treatment in which it cannot be rationalized by signaling since it is common knowledge that a random device generates the initial offer. The results from both sets of experiments cast doubt on the hypothesis that the PFO effect reflects rational optimizing or equilibrium behavior.

The results also raise the question: if rational and anchoring accounts of the PFO effect do not seem to explain it, what are plausible alternative explanations? In our view, some properties of the data can be more readily understood if instead, we think of initial offers as "reference points [which] also affect negotiations by influencing judgments of what is fair or unfair," (Kahneman, 1992, p. 302). Thus, an initial offer can help establish the set of acceptable counteroffers. 
One piece of suggestive evidence on this point comes from looking at the precision of buyers' counteroffers, depending on whether they are responding to a precise or round initial offer. In Study 1, out of 52 buyers who receive a round initial offer, only 1 responds with a precise counteroffer. However, of the 105 buyers who receive a precise initial offer, 17 respond with a precise counteroffer. This difference is statistically significant ( $\mathrm{p}$-value $=0.02$, two-tailed proportions test, see Table A.3), and it suggests that precise offers might induce responders to think differently about what is considered an acceptable counteroffer (e.g. changing their perception of how many "bargaining significant digits" one may consider).

We also find evidence of this phenomenon in Study 2. Pooling across treatments and looking only at the first period of bargaining (and only at those who did not accept the initial offer), we see that only 4 out of 51 subjects responded to a round initial offer with a precise counteroffer, but of the 93 subjects that received a precise initial offer, 31 of them responded with a precise counteroffer. This difference is highly significant in the pooled data ( $\mathrm{p}$-value $<0.01$, two-tailed proportions test) and remains at least marginally significant when we look separately at the data from the Chosen and Random treatments (p-values $=0.03$ and 0.06, respectively, two-tailed proportions tests, see Table A.3).

Turning to the full panel dataset, we construct a dummy indicator that takes a value of 1 if the buyer's counteroffer was precise and 0 otherwise. We then estimate a panel GLS linear probability model in which the dependent variables include a dummy indicator for precise initial offers, a Chosen treatment dummy, an interaction, and both the "Rounds to $\$ 15$ " and "Rounds to \$20" variables to control for the magnitude of the initial offer. We include random effects for each buyer and cluster standard errors at the subject level. The regression indicates that those who receive precise initial offers are consistently more likely to respond with precise counteroffers in the Chosen treatment (see Table A.4). That this effect persists only in the Chosen treatment provides further suggestive evidence that initial offers - when they are chosen (and not random) and thus, in principle, can be meaningful - serve as reference points that shape perceptions about the kinds of counteroffers that are acceptable. 
The notion that round or precise initial offers can serve as reference points which influence the set of acceptable counteroffers is consistent with the novel empirical finding that subjects systematically made more precise counteroffers when responding to precise initial offers. However, the mechanism behind the basic PFO effect remains a puzzle, perhaps a greater puzzle than before, as we both replicate the effect in certain cases and show that the leading rational and behavioral explanations cannot account for it. 


\section{References}

Backus, M., Blake, T. and Tadelis, S. (2019). On the empirical content of cheap-talk signaling: an application to bargaining. Journal of Political Economy, 127(4), 1599-1628.

Janiszewski, C and Uy, D. (2008). Precision of the anchor influences the amount of adjustment. Psychological Science, (19(2), 121-127.

Kahneman, D. (1992). Reference points, anchors, norms, and mixed feelings. Organizational behavior and human decision processes, 51(2), 296-312.

Kristensen, H., and Gärling, T. (2000). Anchor points, reference points, and counteroffers in negotiations. Group decision and negotiation, 9(6), 493-505.

Loschelder, D., Friese, M. and Trötschel, R. (2017). How and why precise anchors distinctly affect anchor recipients and senders. Journal of Experimental Social Psychology, 70, 164-176.

Mason, M ., Lee, A., Wiley, E. \& Ames D. (2013). Precise offers are potent anchors: Conciliatory counteroffers and attributions of knowledge in negotiation. Journal of Experimental Social Psychology, 49 (4) 759-763.

Oesch, J.M. and Galinsky, A.D. (2003). First offers in negotiations: Determinants and effects. Social Science Research Network, online journal

Thomas, M., Simon, D. H., and Kadiyali, V. (2010). The price precision effect: evidence from laboratory and market data. Marketing Science, 29(1), 175-190. 


\section{Appendices to Kimbrough, Porter and Schneider}

\section{A. Additional Figures and Tables}
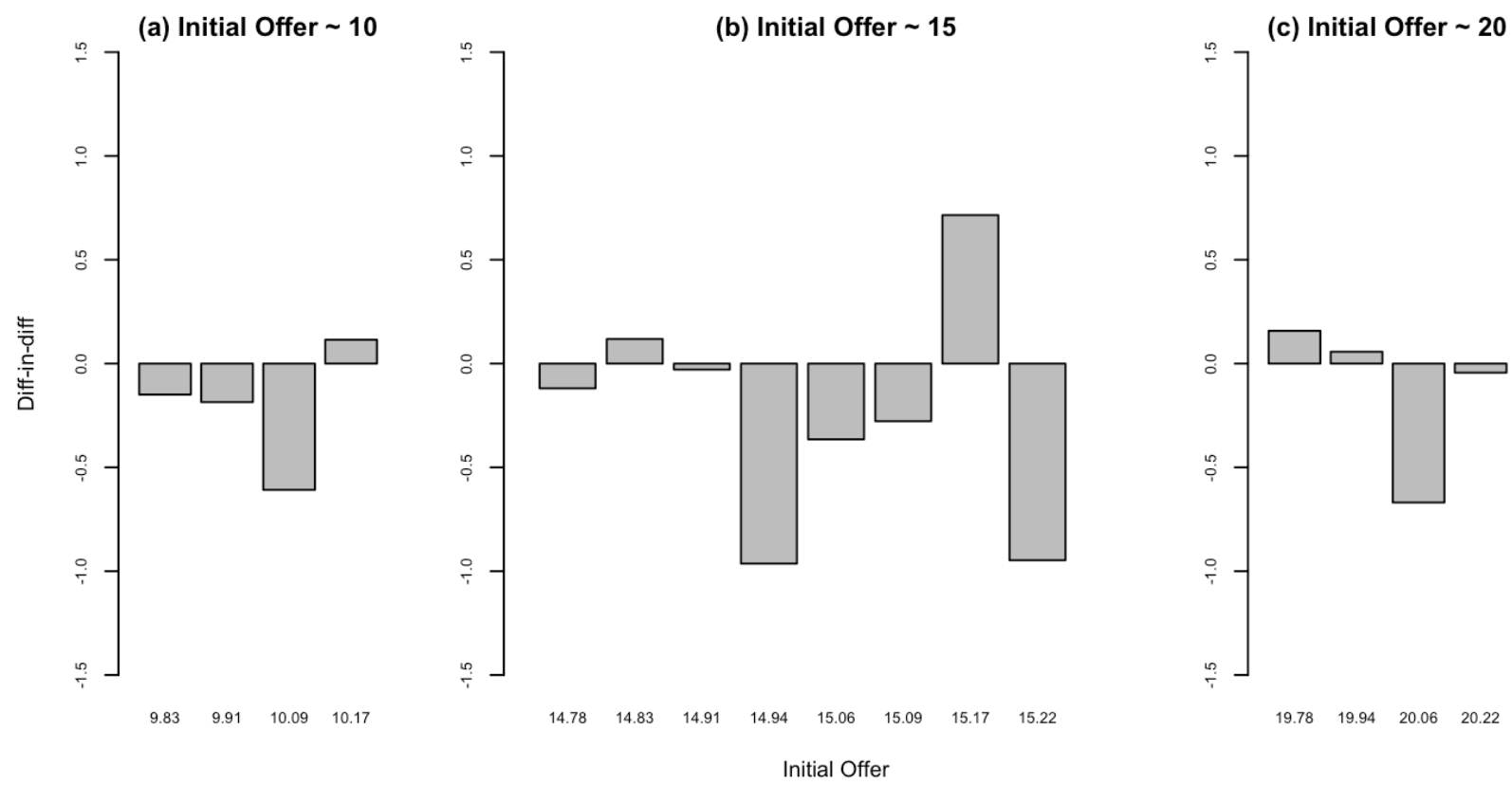

Figure A1. Precise - Round Gap, by Offer Level, Chosen Treatment
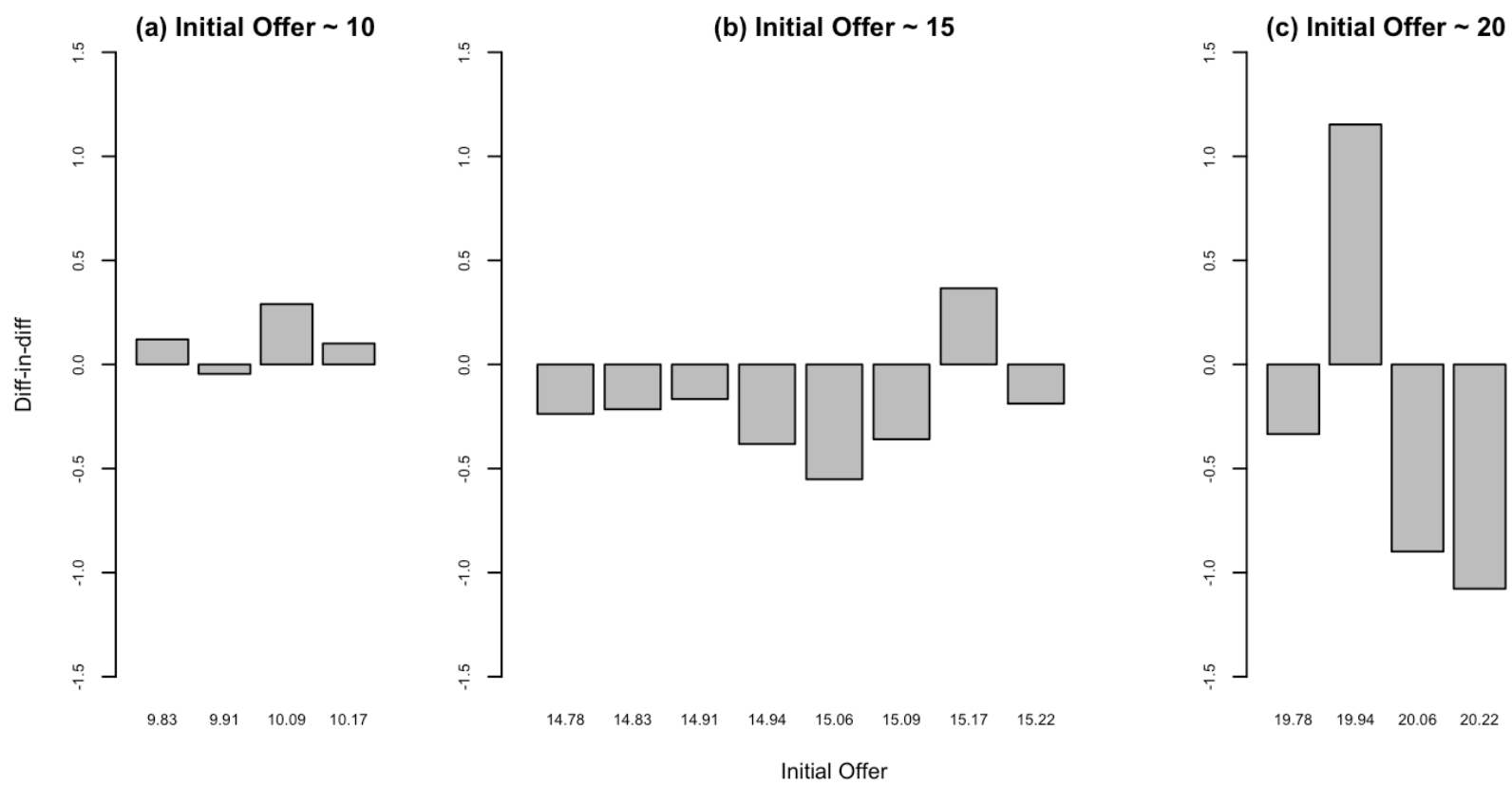

Figure A2. Precise - Round Gap, by Offer Level, Random Treatment 
Table A.1 Panel GLS Regressions of the PFO Effect on Offers and Proportion Accepting, by Treatment with survey measures included.

\begin{tabular}{lll} 
& $(1)$ & $(2)$ \\
& Offer Difference & Accepted the Initial \\
& $(d)$ & Offer $\{0,1\}$ \\
\hline Chosen & -0.24 & -0.03 \\
& $(0.25)$ & $(0.03)$ \\
Precise Offer & $-0.24 * *$ & $-0.05^{* *}$ \\
& $(0.11)$ & $(0.02)$ \\
Chosen X Precise & 0.17 & 0.03 \\
& $(0.18)$ & $(0.03)$ \\
Offer Rounds to 15 & $1.99 * * *$ & $-0.35^{* * *}$ \\
& $(0.13)$ & $(0.03)$ \\
Offer Rounds to 20 & $5.04 * * *$ & $-0.44 * * *$ \\
& $(0.20)$ & $(0.03)$ \\
Risk Taking & 0.01 & -0.00 \\
Optimism & $(0.03)$ & $(0.00)$ \\
CRT & 0.00 & -0.00 \\
Constant & $(0.03)$ & $(0.00)$ \\
& 0.05 & -0.00 \\
Observations & $(0.06)$ & $(0.01)$ \\
\hline
\end{tabular}

Clustered standard errors in parentheses. ${ }^{*} \mathrm{p}<0.1,{ }^{* *} \mathrm{p}<0.05,{ }^{* * *} \mathrm{p}<0.01$ 
Table A.2 Panel GLS Regressions of the Seller's Reject Decision for Counteroffers, by Treatment.

(1)

(2)

\begin{tabular}{lll} 
& Reject $\{0,1\}$ & Reject $\{0,1\}$ \\
\hline Offer Difference & $0.04^{* * *}$ & $0.04^{* * *}$ \\
Chosen & $(0.00)$ & $(0.00)$ \\
& $-0.05^{* *}$ & $-0.05^{* *}$ \\
Precise Offer & $(0.02)$ & $(0.02)$ \\
& $-0.05^{* *}$ & $-0.05^{* *}$ \\
Chosen X Precise & $(0.02)$ & $(0.02)$ \\
& $0.06^{* *}$ & $0.06^{* *}$ \\
Offer Rounds to 15 & $(0.03)$ & $(0.03)$ \\
& $-0.28^{* * *}$ & $-0.28^{* * *}$ \\
Offer Rounds to 20 & $(0.03)$ & $(0.03)$ \\
& $-0.38^{* * *}$ & $-0.38^{* * *}$ \\
Outside Option & $(0.03)$ & $(0.03)$ \\
Risk Taking & $0.01^{* * *}$ & $0.01 * * *$ \\
& $(0.00)$ & $(0.00)$ \\
Optimism & & 0.00 \\
& & $(0.00)$ \\
CRT & & -0.00 \\
Constant & & $(0.00)$ \\
& & -0.00 \\
Observations & 1844 & $(0.00)$ \\
R Sq. & 0.219 & $0.95 * * *$ \\
Clustered & $0.21^{* * *}$ & $(0.13)$ \\
\hline
\end{tabular}

Clustered standard errors in parentheses.

$* \mathrm{p}<0.1, * * \mathrm{p}<0.05, * * * \mathrm{p}<0.01$ 
Table A.3 Period 1 Proportion of Precise Counteroffers by Initial Offer Type

\begin{tabular}{lccc} 
& \multicolumn{3}{c}{ Precise Counteroffer } \\
& Study 1 & Study 2 Chosen & Study 2 Random \\
\hline Round Initial Offer & 0.02 & 0.09 & 0.07 \\
Precise Initial Offer & 0.16 & 0.38 & 0.28 \\
\hline p-value & 0.02 & 0.03 & 0.06 \\
\hline Proportions test & &
\end{tabular}

Table A.4 Proportion of Precise Counteroffers by Initial Offer Type, Over Time

\begin{tabular}{ll} 
& $(1)$ \\
& $\begin{array}{l}\text { Precise Counteroffer } \\
\{0,1\}\end{array}$ \\
\hline Chosen & 0.02 \\
& $(0.04)$ \\
Precise Offer & 0.03 \\
& $(0.03)$ \\
Chosen X Precise & $0.10^{* * *}$ \\
& $(0.04)$ \\
Offer Rounds to 15 & 0.01 \\
& $(0.04)$ \\
Offer Rounds to 20 & -0.06 \\
& $(0.04)$ \\
Constant & $0.23^{* * *}$ \\
& $(0.05)$ \\
\hline Observations & 1844 \\
R Sq. & 0.022 \\
\hline
\end{tabular}




\section{B. Experiment Instructions}

\section{B1. Replication Instructions}

\section{Page 1.}

This is an experiment on economic decision making. Please read the instructions carefully. If you have any questions, raise your hand and an experimenter will answer them privately.

In addition to your $\$ 7$ payment for arriving on time, you will be paid an additional $\$ 5$ upon completing the experiment. Your choices will not affect the final payment you receive. Please respond to the experimental task as honestly as possible. Your responses will help us with our research. Please click the button below to proceed to the experiment.

\section{Page 2.}

You are a college student at the University of Florida. The semester has just ended, and your Introductory Statistics class is over. Because you spent $\$ 50$ of your hard-earned money buying the statistics textbook at the beginning of the semester, you are hoping to recoup some of the cost by reselling it to another student. Earlier in the week, you posted the textbook on an online site that allows University of Florida students to resell their used textbooks. The ad read "Introductory Statistics textbook for sale. Best offer." You have just received a message from a potential buyer interested in purchasing the book. In the message he says that he will give you $\$<$ !--BuyerOffer $\backslash$ in $\{19.85,20.00,20.15\}-->$ for the textbook.

The lowest amount of money for which you are willing to part with the textbook is $\$ 19$. You have the opportunity to make a counteroffer.

The buyer is willing to pay more than he offered, but you are not sure how much more he is willing to pay. If your counteroffer is below the most the buyer is willing to pay for your textbook, the sale takes place at that price, and you receive the amount you offered minus \$19 (which is the lowest amount of money for which you are willing to part with the textbook).

If your counteroffer is above the most the buyer is willing to pay for your textbook, no sale takes place, and you and the buyer each receive $\$ 0$.

Please enter your counteroffer: 


\section{B2. Incentivized Vignette Treatment Instructions}

\section{Page 1.}

This is an experiment on economic decision making. Please read the instructions carefully. If you have any questions, raise your hand and an experimenter will answer them privately.

In addition to your $\$ 7$ payment for arriving on time, you will be paid an additional amount upon completing the experiment. Your choices will affect the final payment you receive. Please respond to the experimental task as honestly as possible. Your responses will help us with our research. Please click the button below to proceed to the experiment.

\section{Page 2.}

You are a college student at the University of Florida. The semester has just ended, and your Introductory Statistics class is over. Because you spent $\$ 50$ of your hard-earned money buying the statistics textbook at the beginning of the semester, you are hoping to recoup some of the cost by reselling it to another student. Earlier in the week, you posted the textbook on an online site that allows University of Florida students to resell their used textbooks. The ad read "Introductory Statistics textbook for sale. Best offer." You have just received a message from a potential buyer interested in purchasing the book. In the message he says that he will give you $\$<$ !--BuyerOffer $\backslash$ in $\{19.85,20.00,20.15\}-->$ for the textbook.

The lowest amount of money for which you are willing to part with the textbook is $\$ 19$. You have the opportunity to make a counteroffer.

The buyer is willing to pay more than he offered, but you are not sure how much more he is willing to pay. If your counteroffer is below the most the buyer is willing to pay for your textbook, the sale takes place at that price, and you receive the amount you offered minus \$19 (which is the lowest amount of money for which you are willing to part with the textbook).

If your counteroffer is above the most the buyer is willing to pay for your textbook, no sale takes place, and you and the buyer each receive $\$ 0$.

Please enter your counteroffer: 


\section{B3. Random Bilateral Bargaining Treatment Instructions}

\section{Instructions for Buyers:}

If you have any questions during the instructions, raise your hand and a monitor will come by to answer your question(s). If any difficulties arise after the experiment has begun, raise your hand, and someone will assist you.

Values in the experiment will be denoted in U.S. Dollars. You will be paid in cash after the experiment. We will pay you exactly your earnings down to the penny.
The experiment will consist of 1 market periods.

Your earnings in each market period are independent. Your earnings for the experiment will be equal to those from 1 randomly selected period.

You have been assigned to be a buyer in the market. Your role will not change throughout the experiment.

There will be 1 buyers and 1 sellers in this experiment.

As a buyer, you will be assigned a value in each market period. Your value will be randomly selected each market period from $[21,22,23,24,25,26]$ with each integer equally likely. Your seller will not know your value. 
You will be able to buy at most one item per period. If you do not buy an item your earnings for the market period will be 0 .

Sellers either have a "low" or "high" outside option. The outside option is a price at which they can sell their item if they don't sell it to you. The "high" and "low" outside options are equally likely to be assigned to the seller. You will not know your seller's outside option.

At the beginning of a market period you will be paired with a seller.

Each market period you will be paired with a new and different seller. Thus you will only pair with each seller once.
At the beginning of a market period the seller will choose a Buy Now Price at which you can immediately purchase the item for sale.

You will be asked to submit a counter-offer back to the seller. If you want to buy the item at the Buy Now

Price, you can submit a counter-offer greater than or equal to the Buy Now Price. If you want to keep bargaining, you can submit a counter-offer lower than the Buy Now Price.

If you successfully purchase the item (either at the Buy Now Price or after bargaining), the market period will end and you will earn: your value - the price

-

$$
\text { The seller earns: the price }
$$


In the examples that follow all the numbers chosen are random and outside of the range of numbers that will be possible in your experiment. You will not see any of these numbers in your actual experiment. 
As a buyer, your 'market screen' is shown to the right Your value for each period is displayed as "My Value." In this example, your value is $\$ 65$.

When the period begins, the seller will have 20 seconds to choose a Buy Now Price. Once the seller has chosen the Buy Now Price, it will appear on your screen

When the Buy Now Price appears on your screen, you will have 30 seconds to submit a counter-offer.

After typing a counter-offer in the white textbox on the Market Screen, the Market Screen will display the profit you would make from your counter-offer IF the seller accepts your offer. This amount is shown as the Potential Profit and it is calculated as your value minus your counter-offer.

If the 30 seconds run out before you submit your counter-offer, your counter-offer will be automatically set equal to the Buy Now Price (\$35), and you will buy at that price.
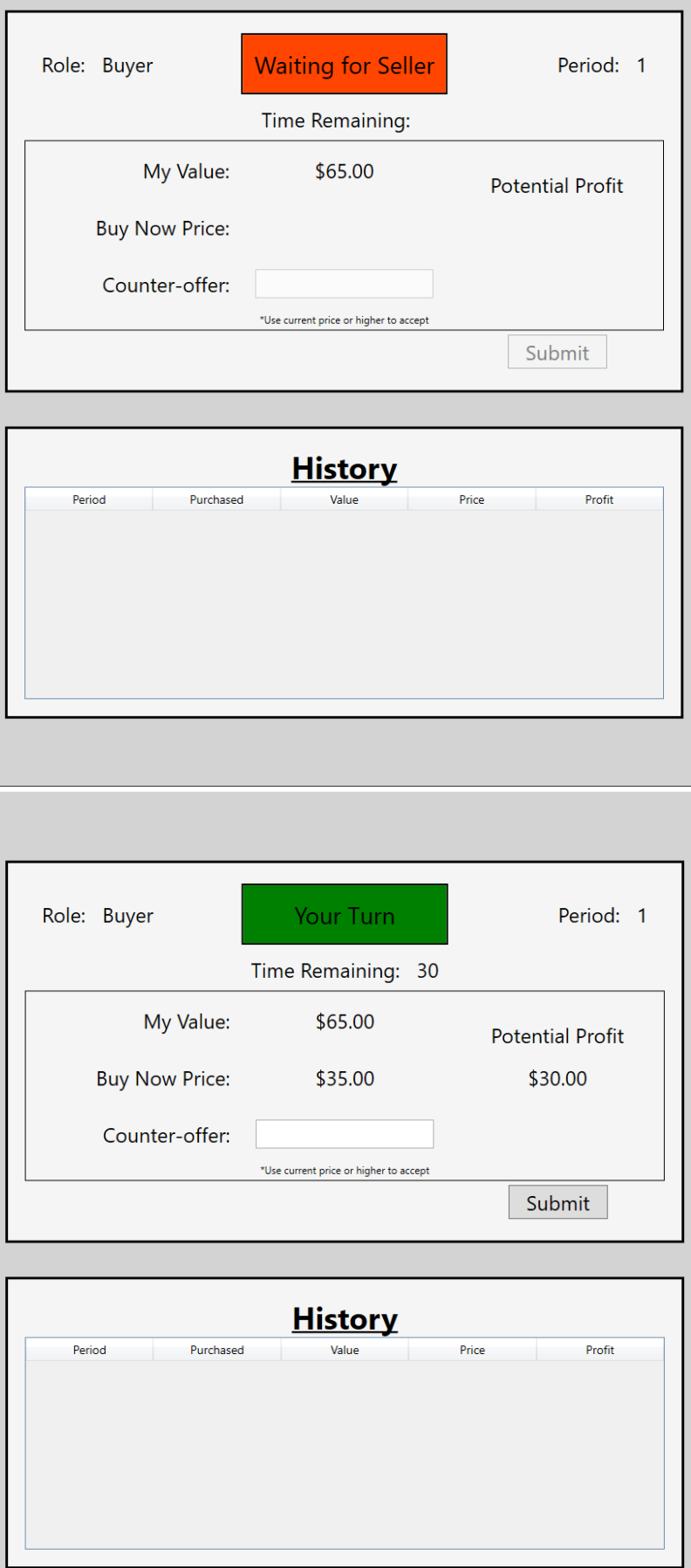
In this example, if you enter a counter-offer of $\$ 35$ or higher, you will purchase the item at the Buy Now

Price of \$35 and receive a prc

$\$ 65-\$ 35=\$ 30$ if this period is randomly selected for your payment.

The seller will receive a profit equal to the Buy Now Price.

Please enter a counter-offer of $\$ 35$ and press submit. There is no need to type a "\$़" next to your counteroffer.

You can specify your counter-offer up to two decimal

Once you have accepted the Buy Now Price you will be able to review the results of that period on your Market Screen prior to the start of the next period. places (i.e., up to pennies).
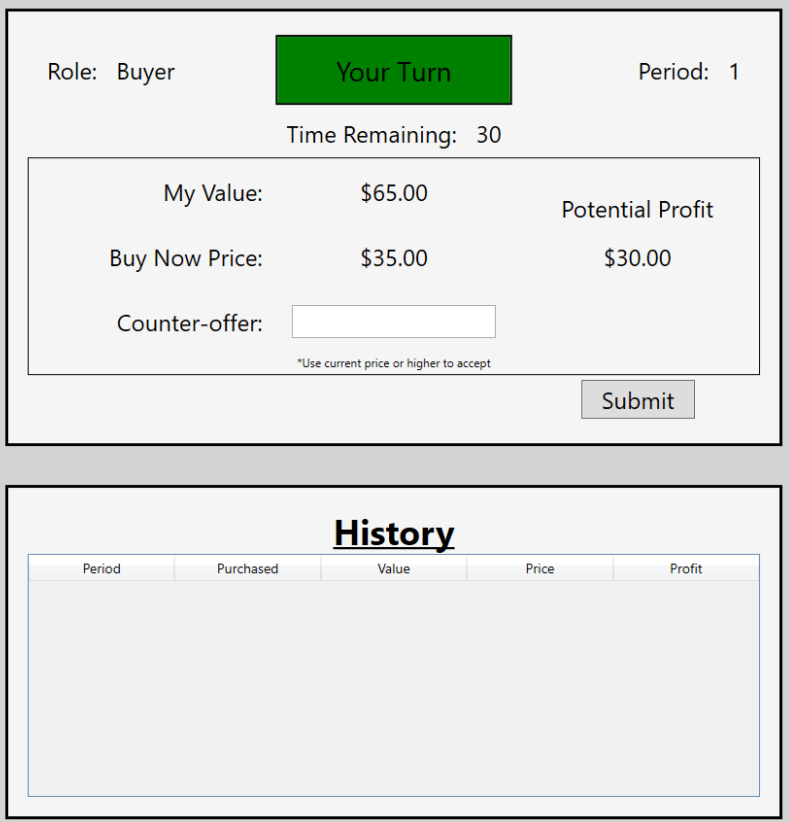

Below your Market Screen, you will see a "History Screen." This screen will be updated after each period and it will display your value, the final price, and your profit from each of the previous periods.

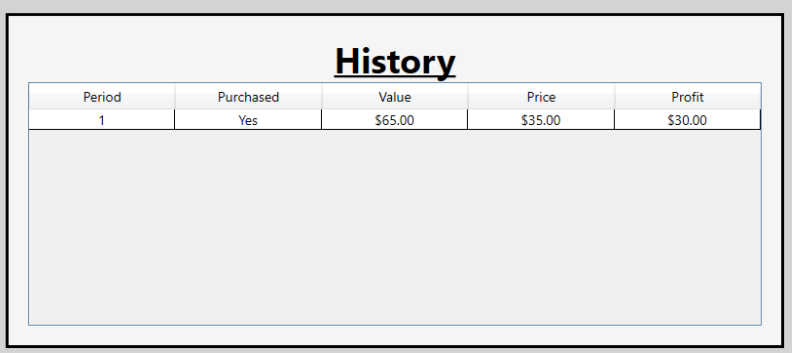


In this next example your value (65) and the Buy Now price (35) remain the same. Go ahead and type in a Counter-offer of 30 .

After you type in 30 click the Submit button to send it to the seller.
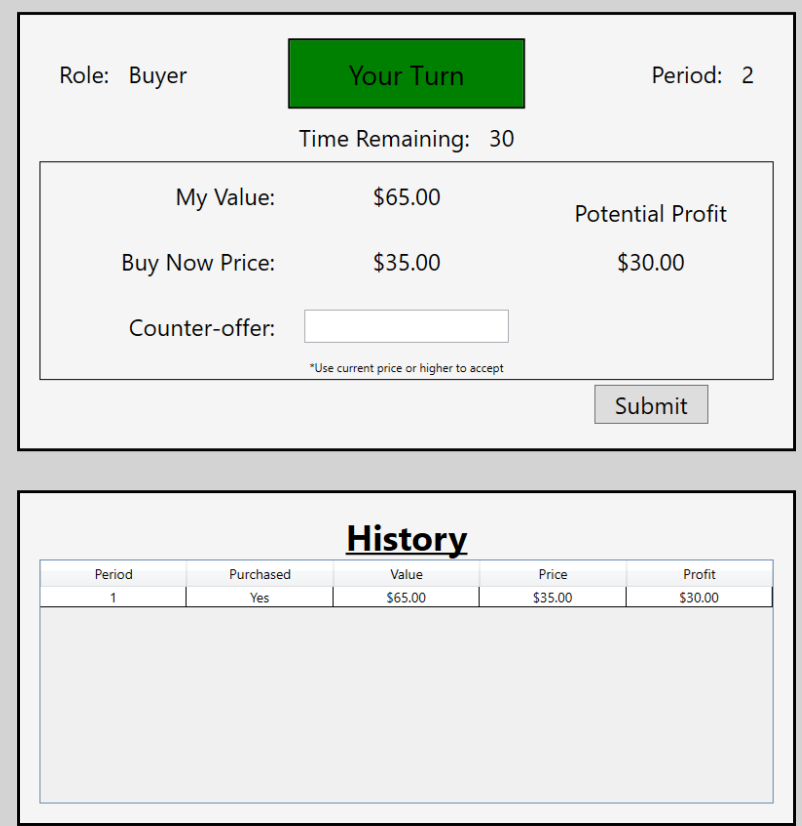

Once you send your Counter-offer to the seller, you will be prompted to wait until the seller accepts or rejects your offer

If the seller accepts you will earn: $65-30=35$ if this period is randomly selected for payment.

If the seller rejects your Counter-offer, the seller receives the value of their outside option, and you receive 0 .

Once the seller makes a decision, you will be able to review the results of that period on your Market

Screen prior to the start of the next period.
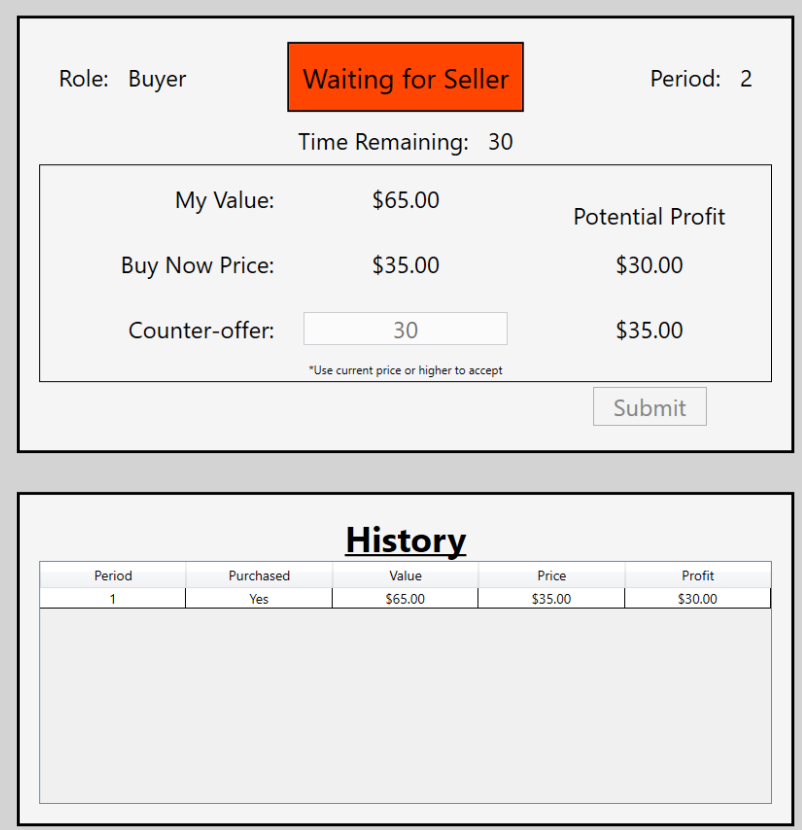
Your earnings in each market period are independent. Your earnings for the experiment will be equal to those from 1 randomly selected period.

Earnings from the randomly selected period are denoted in U.S. Dollars. We will pay you exactly your earnings down to the penny.
You have completed the instructions. You will now take a short quiz about the experiment. You will be paid $\$ 0.5$ for each correct answer.

In the questions that follow, whenever there is an example, all the numbers chosen are random and outside of the range of numbers that will be possible in your experiment. You will not see any of these numbers in your actual experiment.

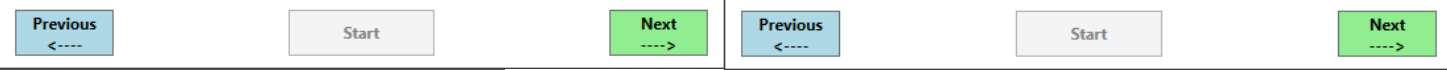

Press start when you are done with the quiz.

After you have pressed start, please wait patiently while everyone else finishes the instructions. 


\section{Buyer's Quiz}

1) If you enter the Buy Now Price as your counteroffer in Period 1 and Period 1 is randomly selected to determine your payment, your profit is:

a. $\$ 0$

b. Your value minus the Buy Now Price

c. Your value minus the Buy Now Price only if the seller accepts your offer

2) If you enter a counteroffer less than the Buy Now Price as your offer in Period 1 and Period 1 is randomly selected to determine your payment, your profit is:

a. $\$ 0$

b. Your value minus the counteroffer

c. Your value minus the counteroffer only if the seller accepts your offer

3) If the Buy Now Price is $\$ 80$ and your value is $\$ 105$, what would be your earnings for this period if you submitted a counteroffer of $\$ 75$ and the seller accepts it. Please type your answer in the box below.

4) If the Buy Now Price is $\$ 80$ and your value is $\$ 105$, what would be your earnings for this period if you submitted a counteroffer of $\$ 75$ and the seller rejects it. Please type your answer in the box below.

5) If you send a counteroffer to the seller, the seller must accept it.
a. Yes
b. No

6) How many periods will you be paid for after the experiment?

7) My value will be the same for every market period of the experiment.
a. Yes
b. No

8) I will be paired with the same seller for every market period.
a. Yes
b. No 


\section{Instructions for Sellers}

If you have any questions during the instructions, raise your hand and a monitor will come by to answer your question(s). If any difficulties arise after the experiment has begun, raise your hand, and someone will assist you.

Values in the experiment will be denoted in U.S. Dollars. You will be paid in cash after the experiment. We will pay you exactly your earnings down to the penny.
The experiment will consist of 1 market periods.

Your earnings in each market period are independent. Your earnings for the experiment will be equal to those from 1 randomly selected period.

You have been assigned to be a seller in the market. Your role will not change throughout the experiment.

There will be 1 buyers and 1 sellers in this experiment.

As a seller, you will be assigned an outside option in each market period. This is the profit you earn if you do not accept the buyer's offer. Your outside option each market period will be either 0 or 9 . It will be selected randomly with each value equally likely. Your buyer will not know the value of your outside option. 
You will be able to sell at most one item per period.

At the beginning of a market period buyers will be assigned a value of the item. You will not know your buyer's value.

At the beginning of a market period you will be paired with a buyer.

Each market period you will be paired with a new and different buyer. Thus you will only pair with each buyer once.
At the beginning of a market period you will select a Buy Now Price from a set of two prices. At the Buy Now Price, the buyer can immediately purchase the item for sale.

The buyer will be asked to submit a counter-offer back to you. If the buyer wants to buy the item at the Buy Now Price, he/she can submit a counter-offer greater than or equal to the Buy Now Price. If the buyer wants to keep bargaining, he/she can submit a counter-offer lower than the Buy Now Price.

If the buyer successfully purchases the item (either at the Buy Now Price or after bargaining) the market period will end and you will earn: the price

The buyer earns: the buyer's value - the price 
We will now go through some examples. In the examples that follow all the numbers chosen are random and outside of the range of numbers that will be possible in your experiment. You will not see any of these numbers in your actual experiment. 
As a seller, your 'market screen' is shown to the right In this example, your Outside Option is \$20.

When the period begins, you can select a price on your Market Screen to be the Buy Now Price for the item. Once submitted, the Buy Now Price will then

appear on the buyer's screen.

Please select a Buy Now Price of $\$ 35$ and press submit.
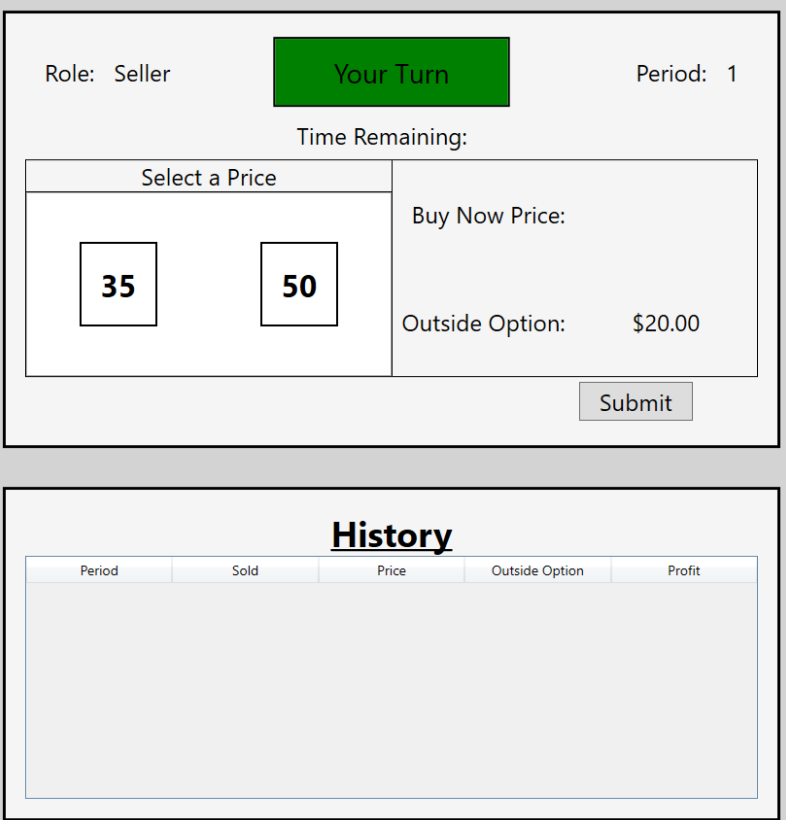

Once the Buy Now Price is submitted it will appear o the buyer's screen and the buyer will have 30 seconds to submit a counter-offer.

Upon receiving the buyer's counter-offer, you will have the option to either accept or reject the offer if the counter-offer is below the Buy Now Price. If the

counter-offer is equal to the Buy Now Price, the sale automatically occurs.

If the 30 seconds run out before the buyer submits

their counter-offer, the buyer will automatically accept

the Buy Now Price.
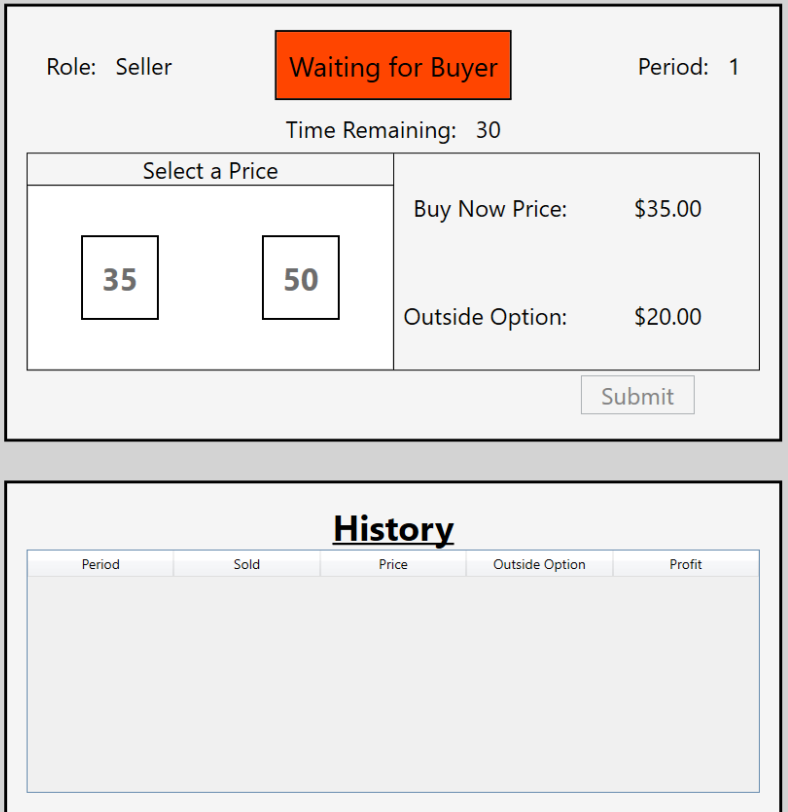


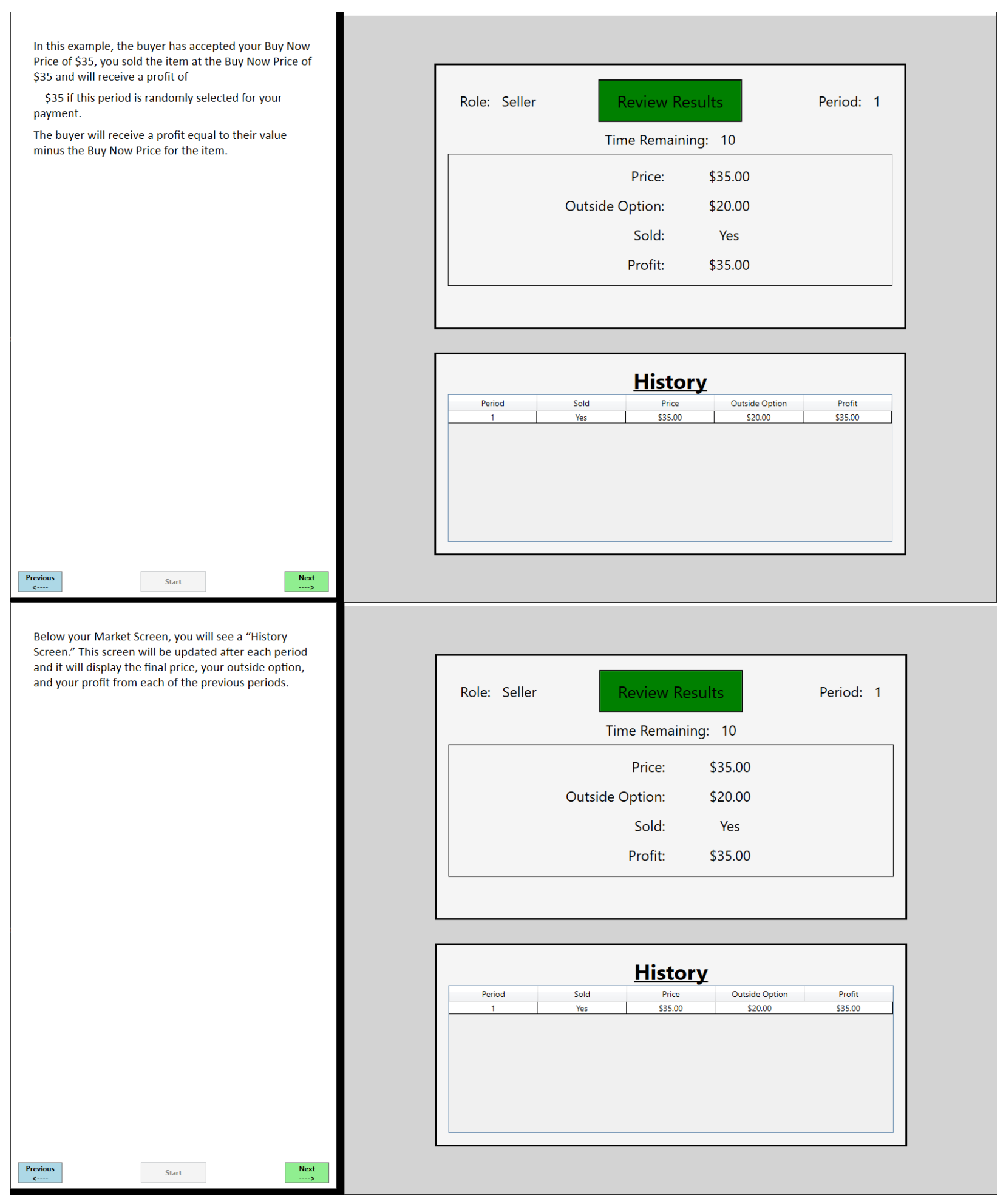


In this next example the Buy Now Price (35) remains the same. You have received a counter-offer of 30 from the buyer.

Upon receiving the buyer's counter-offer, you will have 20 seconds to accept or reject the offer. If you accept the offer, the item is sold and you receive the amount the buyer offered. If you reject the offer, you receive the value of your outside option for this period (\$20).

If the 20 seconds run out before you click the Accept or Reject button, the offer will be automatically rejected.

Please accept or reject the counter-offer now.
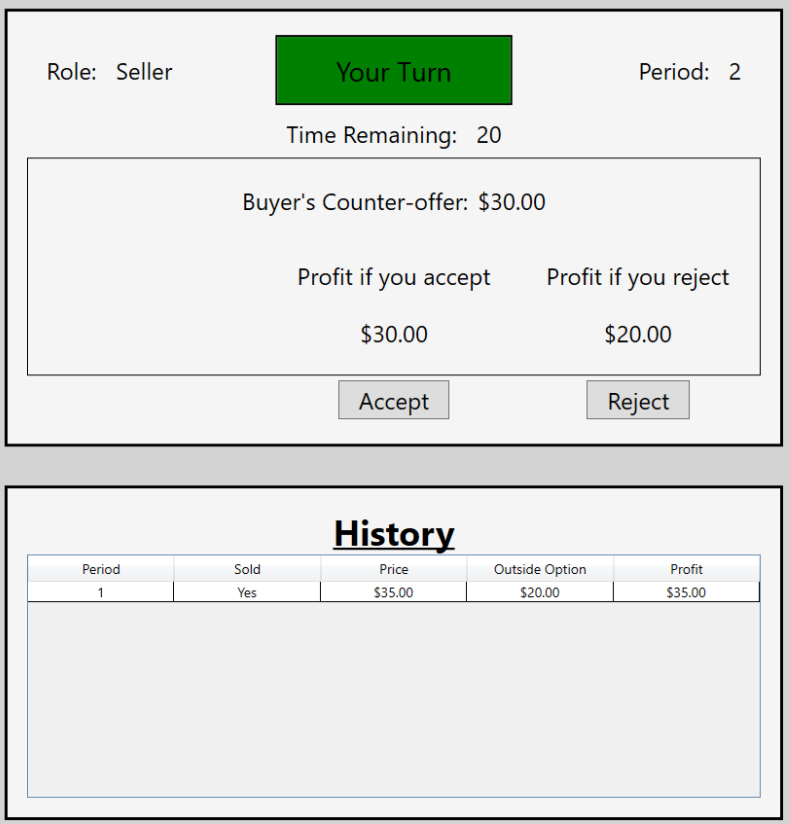
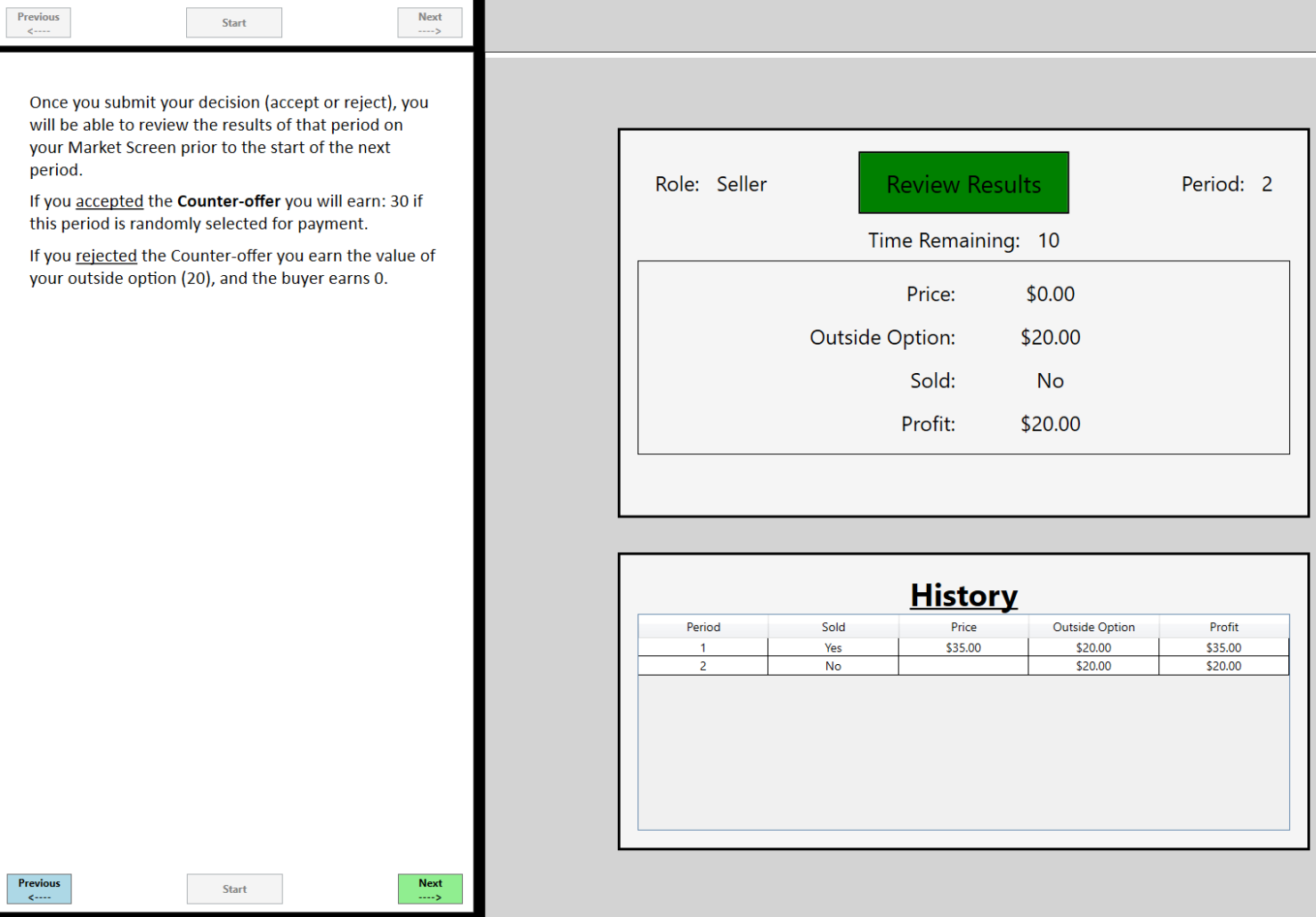


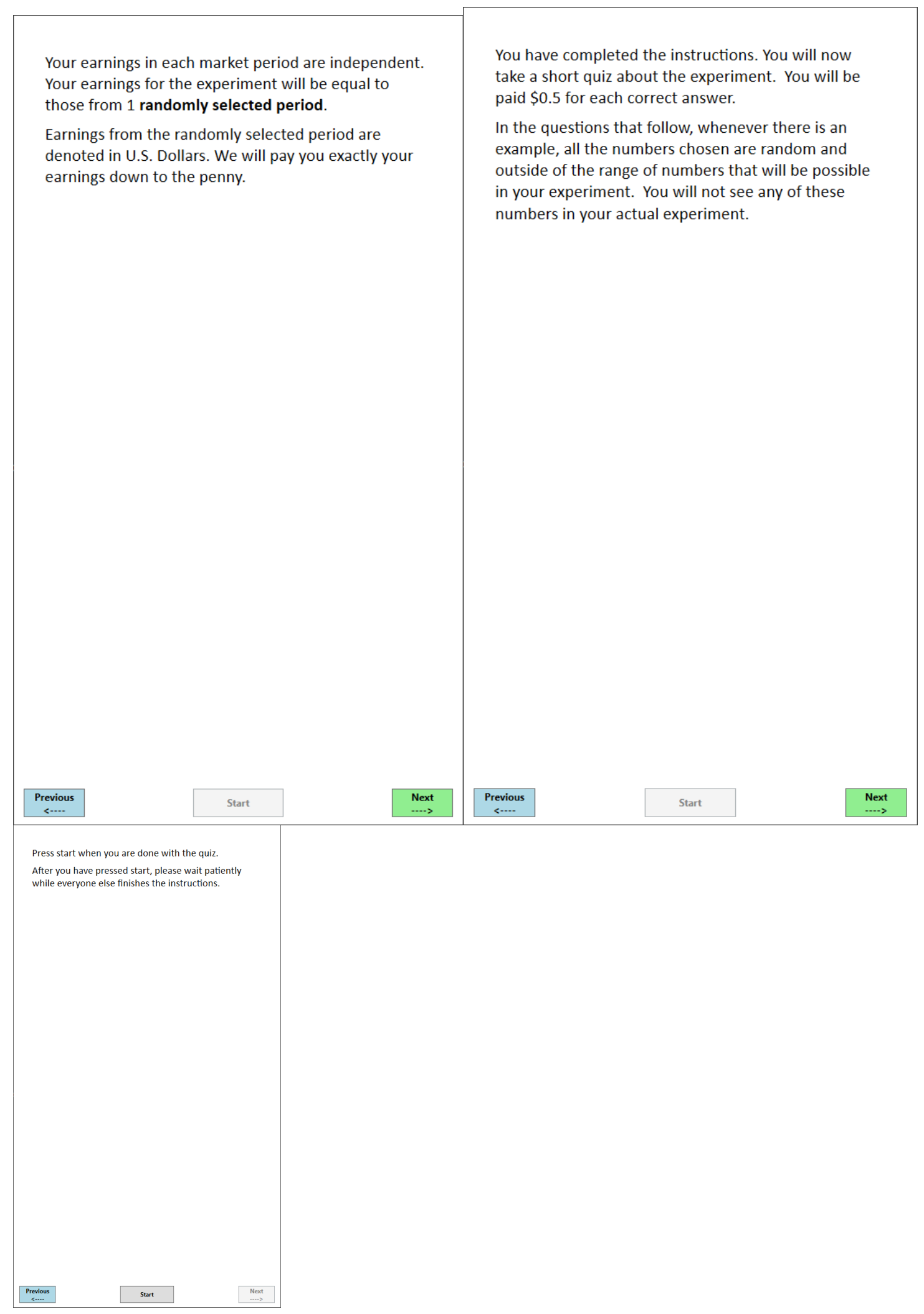




\section{Seller's Quiz}

1) If the buyer enters the Buy Now Price as their counteroffer in Period 1 and Period 1 is randomly selected to determine your payment, your profit is:

a. $\$ 0$

b. The Buy Now Price

c. The Buy Now Price only if you accept their offer

2) If the buyer enters a counteroffer less than the Buy Now Price as their counteroffer in Period 1 and Period 1 is randomly selected to determine your payment, your profit is:

a. $\$ 0$

b. The counteroffer

c. The counteroffer only if you accept their offer

3) If the counteroffer is $\$ 80$ and your outside option is $\$ 60$, what would be your earnings for this period if you accepted the buyer's counteroffer?

4) If the counteroffer is $\$ 80$ and your outside option is $\$ 60$, what would be your earnings for this period if you rejected the buyer's counteroffer?

5) If the buyer sends you a counteroffer, you must accept it.
a. Yes
b. No

6) How many periods will you be paid for after the experiment?

7) My outside option will be the same for every market period of the experiment.
a. Yes
b. No

8) I will be paired with the same buyer for every market period.
a. Yes
b. No 


\section{Post-Experiment Survey}

\section{[CRT]}

1. A bat and a ball cost $\$ 1.10$ in total. The bat costs $\$ 1.00$ more than the ball. How much does the ball cost? \$

2. If it takes 5 machines 5 minutes to make 5 widgets, how long would it take 100 machines to make 100 widgets? minutes

3. In a lake, there is a patch of lily pads. Every day, the patch doubles in size. If it takes 48 days for the patch to cover the entire lake, how long would it take for the patch to cover half of the lake? days

4. If John can drink one barrel of water in 6 days, and Mary can drink one barrel of water in 12 days, how long would it take them to drink one barrel of water together? days

5. Jerry received both the $15^{\text {th }}$ highest and the $15^{\text {th }}$ lowest mark in the class. How many students are in the class? students

6. A man buys a pig for $\$ 60$, sells it for $\$ 70$, buys it back for $\$ 80$, and sells it finally for $\$ 90$. How much has he made? dollars

7. Simon decided to invest $\$ 8,000$ in the stock market one day early in 2008 . Six months after he invested, on July 17, the stocks he had purchased were down 50\%. Fortunately for Simon, from July 17 to October 17, the stocks he had purchased went up 75\%. At this point, Simon has:

a. broken even in the stock market

b. is ahead of where he began

c. has lost money 


\section{[Optimism]}

How much do you agree with each of the following statements?

\begin{tabular}{|l|l|l|l|l|l|}
\hline & $\begin{array}{l}\text { I disagree a } \\
\text { lot }\end{array}$ & $\begin{array}{l}\text { I disagree a } \\
\text { little. }\end{array}$ & $\begin{array}{l}\text { I neither } \\
\text { agree nor } \\
\text { disagree }\end{array}$ & $\begin{array}{l}\text { I agree a } \\
\text { little }\end{array}$ & $\begin{array}{l}\text { I agree a } \\
\text { lot. }\end{array}$ \\
\hline $\begin{array}{l}\text { In uncertain times, I usually } \\
\text { expect the best. }\end{array}$ & 1 & 2 & 3 & 4 & 5 \\
\hline $\begin{array}{l}\text { It's easy for me to relax. } \\
\begin{array}{l}\text { If something can go wrong for } \\
\text { me, it will. }\end{array}\end{array}$ & 1 & 2 & 3 & 4 & 5 \\
\hline $\begin{array}{l}\text { I'm always optimistic about } \\
\text { my future. }\end{array}$ & 1 & 2 & 3 & 4 & 5 \\
\hline I enjoy my friends a lot. & 1 & 2 & 3 & 4 & 5 \\
\hline $\begin{array}{l}\text { It's important for me to keep } \\
\text { busy. }\end{array}$ & 1 & 2 & 3 & 4 & 5 \\
\hline $\begin{array}{l}\text { I hardly ever expect things to } \\
\text { go my way. }\end{array}$ & 1 & 2 & 3 & 4 & 5 \\
\hline I don't get upset too easily. & 1 & 2 & 3 & 4 & 5 \\
\hline $\begin{array}{l}\text { I rarely count on good things } \\
\text { happening to me. }\end{array}$ & 1 & 2 & 3 & 4 & 5 \\
\hline $\begin{array}{l}\text { Overall, I expect more good } \\
\text { things to happen to me than } \\
\text { bad. }\end{array}$ & 1 & 2 & 3 & 4 & 5 \\
\hline
\end{tabular}

\section{[Risk Attitude]}

How likely are you to engage in each of the following behaviors?

\begin{tabular}{|l|l|l|l|l|l|}
\hline & $\begin{array}{l}\text { Highly } \\
\text { Unlikely }\end{array}$ & Unlikely & Neutral & Likely & $\begin{array}{l}\text { Highly } \\
\text { Likely }\end{array}$ \\
\hline Betting a day's income at the horse races & 1 & 2 & 3 & 4 & 5 \\
\hline $\begin{array}{l}\text { Betting a day's income at a high stakes poker } \\
\text { game }\end{array}$ & 1 & 2 & 3 & 4 & 5 \\
\hline $\begin{array}{l}\text { Betting a day's income on the outcome of a } \\
\text { sporting event }\end{array}$ & 1 & 2 & 3 & 4 & 5 \\
\hline $\begin{array}{l}\text { Investing 10\% of your annual income in a } \\
\text { moderate growth diversified fund }\end{array}$ & 1 & 2 & 3 & 4 & 5 \\
\hline $\begin{array}{l}\text { Investing 5\% of your annual income in a } \\
\text { speculative stock }\end{array}$ & 1 & 2 & 3 & 4 & 5 \\
\hline $\begin{array}{l}\text { Investing 10\% of your annual income in a } \\
\text { new business venture. }\end{array}$ & 1 & 2 & 3 & 4 & 5 \\
\hline
\end{tabular}




\section{[Political Identity]}

1a) Generally speaking, do you usually think of yourself as a Republican, a Democrat, an Independent, or what?" (with a drop down menu with Republican, Democrat, Independent, Other as options.)

The survey is then adaptive, depending on the response given:

1b.1) (IF REPUBLICAN OR DEMOCRAT) "Would you call yourself a strong (REPUBLICAN/DEMOCRAT) or a not very strong (REPUBLICAN/DEMOCRAT)?"

1b.2) (IF INDEPENDENT, OTHER) "Do you think of yourself as closer to the Republican or Democratic party?"

2) Here is a 7-point scale on which the political views that people might hold are arranged from extremely liberal to extremely conservative.

Where would you place yourself on this scale, or haven't you thought much about this?

1. Extremely Liberal

2. Liberal

3. Slightly Liberal

4. Moderate, Middle of Road

5. Slightly Conservative

6. Conservative

7. Extremely Conservative

DK, Haven't Thought About it

\section{[Program of Study]}

In which school/college will you complete your major?

(drop down menu with Argyos School of Business and Economics, College of Educational Studies, Dodge College of Film and Media Arts, Wilkinson College of Humanities and Social Sciences, Fowler School of Law, College of Performing Arts, Schmid College of Science and Technology, School of Pharmacy, Crean School of Health and Behavioral Science, Other) 